\title{
Cellular Analogs of Visual Cortical Epigenesis. II. Plasticity of Binocular Integration
}

\author{
Daniel Shulz and Yves Frégnac \\ Laboratoire de Neurobiologie et Neuropharmacologie du Développement, Université Paris XI, F-91405 Orsay Cedex, \\ France
}

Two differential pairing procedures were applied in the primary visual cortex of anesthetized and paralyzed kittens and cats, to produce changes in ocular dominance and interocular orientation disparity (IOD) during the time of recording of a single neuron.

A first experiment was devised to demonstrate plasticity in the balance of monocular responses. The visual activity of the cell was driven iontophoretically to either a "high" or a "low" level, depending on the ocularity of the visual stimulation. Ocular dominance measurements before and after pairing revealed significant long-lasting changes in $33 \%$ of cases. Relative ocular preference shifted in most cases $\mathbf{( 8 7 . 5} \%)$ in favor of the reinforced eye. Similar proportions of significant changes were observed in kitten and adult cortex. The amplitude of the functional modifications was not significantly related with age, although the largest changes in ocular dominance were recorded at the peak of the critical period.

The second experiment more specifically addressed the plasticity of binocular interaction. The activity of a binocular cell was driven iontophoretically to either a "high" or a "low" level, depending on the orientation disparity between two oriented stimuli, presented simultaneously and separately in the receptive field of each eye. Significant long-lasting changes in binocular responses were induced in $40 \%$ of cases. The relative IOD preference generally shifted (67\%) in favor of the reinforced disparity. In half of the modified cells, functional changes were expressed only in the dichoptic viewing condition used during the pairing procedure.

These functional modifications of binocular integration, demonstrated at the cellular level, are analogous to those induced by global manipulations of the visual environment (Hubel and Wiesel, 1970; Shinkman and Bruce, 1977). They are interpreted as evidence for synaptic plasticity. Our results support the hypothesis that covariance levels between pre- and postsynaptic activities determine the sign and the amplitude of changes in synaptic efficacy.

Received Mar. 7, 1991; revised Oct. 31, 1991; accepted Nov. 5, 1991.

This work was supported by grants from the CNRS (AIP85-06931), MRES (84C1307 and 87C0187), FRM, and HFSP to Y.F. D.S. was supported by the Cino del Duca and Singer-Polignac Foundations during his $\mathrm{PhD}$ studies. We thank Drs. E. Bienenstock, F. Crépel, M. J. Friedlander, and H. Kennedy for helpful comments, Dr. S. Thorpe and K. Grant for help with the English, and Michele Gautier for technical assistance.

Correspondence should be addressed to Drs. Yves Frégnac and Daniel Shulz, Laboratoire de Neurobiologie et Neuropharmacologie du Développement, Bât 440, Université Paris XI, F-91405 Orsay Cedex, France.

Copyright (C) 1992 Society for Neuroscience $0270-6474 / 92 / 121301-18 \$ 05.00 / 0$
In the preceding companion article (Frégnac et al., 1992), a cellular analog of plasticity of orientation selectivity was presented, which demonstrates functional changes similar to those occurring during normal or abnormal visual development during the time of recording of a single neuron (Frégnac et al., 1988, 1992). The present report focuses on the role of temporal correlation between pre-and postsynaptic activity in the plasticity of ocular dominance (experiment 1) and of interocular orientation disparity (IOD) (experiment 2).

These two receptive field properties concern two aspects of neural integrative processes thought to subserve cortical functions such as binocular fusion, rivalry, and stereopsis. The first characterizes the interocular balance between excitatory and inhibitory input from each eye (Hubel and Wiesel, 1962; Sillito et al., 1980; Kato et al., 1981), which could have a role in stereoscopic depth perception (Gardner et al., 1985). The second concerns more specifically binocular interaction between monocular afferent messages in the orientation domain (Blakemore et al., 1972) and might be implicated in the perception of stimuli tilted in depth. Numerous studies have shown that the development of these two binocular cortical functions is dependent on early visual experience (reviewed in Movshon and Van Sluyters, 1981; Frégnac and Imbert, 1984). Knowledge on these activity-dependent changes so far relies on comparing the properties of populations of neurons recorded in different animals submitted to global environmental manipulations [deprivation of patterned vision to one eye (Wiesel and Hubel, 1963), surgical (Hubel and Wiesel, 1965) or optical (Van Sluyters and Levitt, 1980) misalignment of the visual axes, and optical rotation of the monocular images (Shinkman and Bruce, 1977)].

The loss of binocularity following monocular deprivation or optical strabismus contrasts with the absence of change produced by binocular deprivation of visual input. This indicates that binocular competitive interaction between visual inputs for dominance of central connections-rather than disuse of the deprived eye-appears to be the major mechanism involved in monocular deprivation effects. Further demonstration that an imbalance of afferent retinal activity per se is responsible for the change in ocular dominance distribution was made using protocols combining intraocular injection of TTX with either monocular deprivation (Chapman et al., 1986) or electrical stimulation of the optic nerves (Stryker, 1986).

Monocular deprivation appears as a standard paradigm for the estimation of the level of plasticity in the developing cortex. Hubel and Wiesel (1970; see also Olson and Freeman, 1980), in a series of pioneering studies, defined a critical period of susceptibility to binocular imbalance, extending from the third postnatal week to 3 months of age in the cat. Subsequent studies, 
using longer periods of monocular deprivation, showed that the decrease of sensitivity is more gradual than initially proposed (Cynader and Mitchel, 1980; Jones et al., 1984) and is not homogeneous throughout the different layers of the cortex (Fox et al., 1989). It has nevertheless been found that no change in ocular dominance is observed when monocular deprivation intervenes over 1 year of age (N. W. Daw, K. Fox, H. Sato, and D. Czepita, unpublished observations).

The peak of sensitivity to monocular deprivation occurs at the beginning of the critical period (between 4 and 6 weeks of agc), and a few hours of monocular vision has been shown to be sufficient at that age to induce a long-lasting dominance of the open eye at the cortical level (Schechter and Murphy, 1976; Movshon and Dürsteler, 1977; Freeman and Olson, 1979; Trotter et al., 1983). Such changes seem too rapid to result from anatomical disconnection of the deprived afferents. A possible explanation could be selective activity-dependent changes in the efficacy of transmission at excitatory synapses mediating visual activity (Blakemore et al., 1976; but see also Singer, 1977). Evidence supporting this assumption was provided recently by chronic multiunit recordings from striate cortex of awake animals, where eye closure initially induced a decrease of the excitatory response to the stimulation of the deprived eye, followed occasionally by a progressive increase of the response evoked through the experienced eye (Mioche and Singer, 1989).

Such studies, reporting rapid changes in ocular dominance, address one major aspect of the mechanisms responsible for plasticity of binocular integration. However, the classical definition of an "ocular dominance" index, used in most of these studies, does not take into account possible spatial and temporal interactions between monocular afferent messages converging on binocular neurons. This can be revealed under binocular viewing conditions when differences in the organization and/or in the stimulation of the two receptive fields selectively affect the binocular response (Freeman and Ohzawa, 1990). For example, significant differences in the preferred orientation seen through each eye, that is, IOD, can be observed in cortical neurons both in adult cats and kittens. The IOD property could allow the relative position and angle of tilt of objects in space to be determined, using disparity cues from discordant orientations that result from the horizontal separation of the two eyes (Blakemore et al., 1972; but see Nelson et al., 1977).

Devclopmental studies (Blakemore and Van Sluyters, 1974, 1975) suggest that binocular visual experience is needed to match functional selectivity in the two eyes. This conclusion was further confirmed by experiments restricting the binocular correspondence of monocular images (Shinkman and Bruce, 1977; Dürsteler and von der Heydt, 1983). Shinkman and colleagues studied extensively the cortical effects of rearing kittens with prisms that imposed separate rotations around the visual axis of the otherwise unaltered monocular images (reviewed in Shinkman et al., 1985). Systematic differences between the preferred orientations seen through each eye were found that corresponded on average to the IOD imposed during the prism viewing condition. Such adaptations, described in kittens as old as 5 months of age, appeared maximal when manipulation of the coherence between the monocular images was imposed from 4 to 6 weeks of age.

The electrophysiological data presented above have been taken to support Hebbian schemes of plasticity (Hebb, 1949; Stent, 1973; see also Cynader and Mitchel, 1977; Rauschecker and Singer, 1981), which suggest that global functional modifications result from gains and losses in the efficacy of synaptic transmission. Increases in synaptic efficacy are supposed to be produced by maintained temporal correlation between postsynaptic activity and presynaptic activity, which in the present case mainly originates from fibers subserving the open eye or are selectively activated by the binocularly experienced stimulus configuration. However, despite the coherence of experimental observations based on population analysis, little is known on the plasticity of monocular and binocular integrative processes at the single-cell level. To understand the activity requirements in the induction of such phenomena, the observation in acute preparations of functional changes during the time of recording of a single cell appears a more suitable experimental situation than comparing the initial and final functional states of the entire cortex after a global manipulation of the visual input. The former strategy will allow the determination of the conditions required to modify the integrative power of a single neuron. The present study at the single-cell level was designed to reproduce functional changes analogous to those observed during normal and abnormal development of binocular integration, by a local manipulation of the temporal correlation between the afferent activity and the postsynaptic visual response (see "covariance hypothesis" in Frégnac et al., 1992, introductory remarks).

Preliminary accounts of these data have been given elsewhere (Frégnac and Shulz, 1987; Shulz, 1987; Frégnac et al., 1988).

\section{Experiment 1: Plasticity of Ocular Dominance}

A cellular analog of ocular dominance plasticity was developed in which visual stimulation through one eye was paired with an increase in response of the recorded cell, whereas stimulation of the other eye was paired with a reduction or blockade of the response by iontophoretic means. Assuming that presynaptic activity is affected to a much lesser extent by the iontophoretic action than postsynaptic activity (see Discussion in Frégnac et al., 1992), such external control of the firing level should be an effective way of extracellularly imposing different levels of covariance between pre- and postsynaptic activity for separate visual afferent messages. This differential pairing procedure, applied in both kitten and adult area 17, produced significant longterm changes in ocular dominance while recording from a single neuron.

\section{Materials and Methods}

Rearing conditions. Thirteen animals from the laboratory breeding colony were used, among which four were 5-8-week-old normally reared kittens, one was a 7.5-week-old dark-reared kitten, and eight were normally reared adult cats older than 1 year of age.

Surgical preparation. Details of the surgical and electophysiological procedures, as well as the iontophoretic method devised to control the level of cortical activity are given in the companion article (Frégnac et al., 1992).

Visual stimulation and pairing protocol. $\Lambda$ fter qualitative determination of the optimal stimulation parameters, ocular dominance was quantitatively studied by a computer-assisted presentation of the preferred orientation in blocks of eight trials (four for each eye) until each eye had been stimulated alternately at least 40 times. During pairing, the presentation of the preferred orientation through one eye (in most cases the nondominant eye) was associated with an increase in discharge imposed by a concomitant positive current pulse, applied through the recording $\mathrm{KCl}$ electrode and maintained during the sweep of the stimulus across the receptive field $\left(\mathrm{S}^{+} ;\right.$Fig. 1$)$. Alternately the presentation of the same orientation through the other eye was associated with a decrease of the visual activity imposed by a pulse of negative current (S- Fig. 1). After pairing, a control period of visual stimulation (without 
a

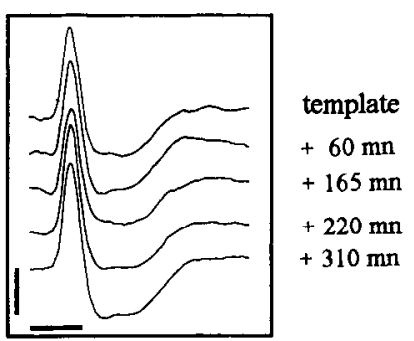

b EXPERIMENT 1

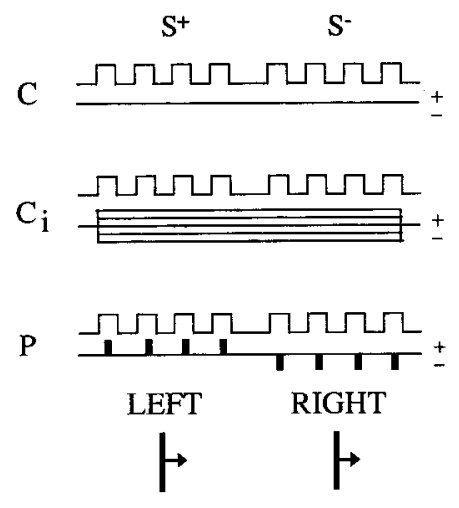

C EXPERIMENT 2

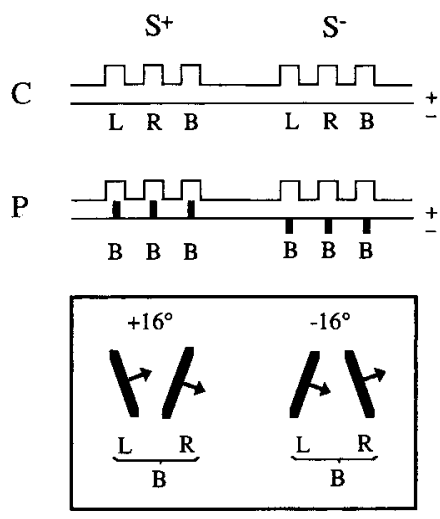

TUNING CURVES

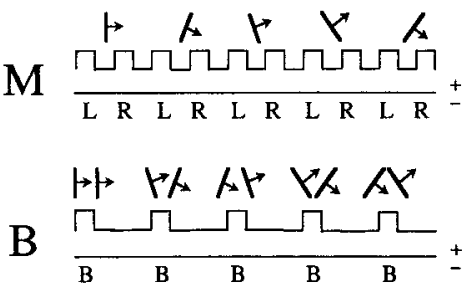

Figure 1. Protocols of imposed temporal correlation between visual afferent activity and postsynaptic firing. $a$, For each cell, the shape of the action potential (calibration: $1 \mathrm{mV}, 1 \mathrm{msec}$ ) was continuously monitored on a digital oscilloscope and compared to an initial template to ensure that the same neuron was recorded throughout the experiment. $b$. Experiment 1: ocular dominance. Each square pulse (upper lines) indicates the temporal occurrence of a single visual stimulation, and each solid rectangle, that of an iontophoretic pulse (lower lines) of a given polarity (shown at right). During controls $\left(C\right.$ and $\left.C_{i}\right)$, one stimulus of fixed orientation was presented four times to one eye and then four times to the other ( $S^{+}$ and $\left.\mathrm{S}^{-}\right)$, without current $(C)$ or at a constant level of iontophoretic current $\left(C_{i}\right)$. This elementary sequence was repeated 10-50 times. During pairing $(P)$, iontophoretic pulses were concomitant with the visual response, in such a way as to impose a significant increase $\left(\mathrm{S}^{+}\right)$or decrease $\left(\mathrm{S}^{-}\right)$of the visual response. Cases where no modulation of activity could be produced by iontophoresis are noted $\mathrm{S}^{0}$ (see right eye stimulation in Fig. 4 ). $c$, Experiment 2: IOD. During control $(C)$, two series of stimulus configurations were presented $\left(S^{-},-16^{\circ} ; S^{+},+16^{\circ}\right.$; see inset). The left eye component $(L)$ and the right eye component $(R)$ of the dichoptic stimulus as well as the dichoptic stimulus itself $(B)$ were presented 10 times. During pairing $(P)$, iontophoretic pulses were concomitant with the visual response evoked by binocular stimuli $(B)$ presented by blocks of 30 trials. Tuning curves, In order to study the generalization for disparities other than the two that were experienced during pairing, the experimentally observed binocular response $(B)$ for orientation disparity ranging from $-90^{\circ}$ to $+90^{\circ}$ was compared with the sum of the monocular responses for each component of the dichoptic configuration $(M)$ for the same disparity value. Randomized presentation of a given IOD configuration (chosen among seven fixed values: $\left.-90^{\circ},-45^{\circ}-16^{\circ}, 0^{\circ},+16^{\circ},+45^{\circ},+90^{\circ}\right)$ was interleaved with the alternate presentation of the respective orientation $\left(325^{\circ}, 338.5^{\circ}, 352^{\circ}\right.$, $\left.0^{\circ}, 8^{\circ}, 22.5^{\circ}, 45^{\circ}\right)$ shown to each eye ( $L$, left eye; $R$, right eye), and the whole sequence was repeated at least three times.

iontophoretic current) was repeated in order to measure posssible changes in ocular dominance.

Data analysis. An index of ocular dominance (ocular dominance ratio, or ODR), given by the normalized ratio of visual responses $\mathrm{S}^{+} /\left(\mathrm{S}^{-}+\right.$ $\mathrm{S}^{+}$), was computed using a moving average technique (see Frégnac et al., 1992). This index and the mean visual activity were calculated on successive blocks of eight trials (four for each eye) during both controls and pairing periods, and the distributions of ODR values established before, during, and after pairing were compared statistically using parametric (unpaired Student's $t$ test, significance level of $p<0.005$ ) and nonparametric tests [Kolmogorov-Smirnov test (KS), significance level of $p<0.05$ ). For the four monocular cells studicd, similar statistical analysis was carried out in which the relative ocular dominance ratio was replaced by the absolute mean visual activity (see Fig. 7). In the case of a pairing procedure restricted to a subzone within a multimodal receptive field, partial ocular dominance ratios were calculated for both paired and unpaired regions of the receptive field (see Fig. 4 caption).

In addition to the ocular dominance ratio, which gives an estimate of the competitive advantage imposed between the two paired stimuli, the quality of the control of visual activity during pairing was classified into three categories ("null," "partial," or "complete" actions) in order to determine whether a significant modulation of postsynaptic firing was achieved for both test stimuli and restricted to the iontophoretic period (see Materials and Methods in Frégnac et al., 1992).

\section{Results}

Fifty-four visual cells were recorded in primary visual cortex, including 15 in normally reared kittens, 4 in a dark-reared kitten, and 35 in normal adult cats. Twenty-four of these cells were submitted to 43 differential pairing procedures. The other 30 cells were used for control of temporal stability and dependence with constant iontophoretic current (see Figs. 1b,2).

\section{Intrinsic variability of ocular dominance}

A study of the temporal stability of ocular dominance was made in all 54 cells; 13 of these were recorded over several hours. The results indicate that the ocular dominance remained stable and did not show significant trends with time (Fig. $2 a$ ), although it was more variable than orientation selectivity (see Frégnac et al., 1992). Its level of intrinsic variability appears to be independent of the age of the animal. These observations confirm previous studies (Macy et al., 1982) that have used alternate stimulation of both eyes (Hammond, 1981) to obtain an unbiased estimation of ocular dominance. 
a

Figure 2. Intrinsic variability of ocular dominance. $a$. Temporal stability: recordings of a simple cell (for $60 \mathrm{~min}$ ) in a normal adult cat over 1 year of age. Dot displays of the spontaneous and visual activity (each point corresponds to the temporal occurrence of one action potential) are shown in response to alternate stimulations of an optimally oriented bar through each eye. Brackets below each dot display indicate the periods chosen for the cumulative integration of the visual response used to compute ODR ratios shown to the right. Temporal evolution of this ratio- $\mathrm{S}^{+} /$ $\left(\mathrm{S}^{+}+\mathrm{S}^{-}\right)$(calculated by a moving average technique on four pairs of successive stimulation)-is plotted from $t o p$ to bottom, and the initial mean value corresponding to the first control period is indicated by a solid line (ODR $=0.5$ ). No statistically significant difference was found between this value and those calculated for each of the successive control periods. $b$, Iontophoretic current dependence: in contrast to the cell shown in $a$, significant relationships between the ODR and the mean level of visual activity were found in two neurons recorded in adult cats. These cells tended to be activated more binocularly (i.e., ODR shifted toward 0.5 ) with increasing levels of activity imposed by iontophoretic action (Left; $r=+0.61, F$ test $p<0.0001, \mathrm{df}=56 ;$ Right; $r=$ $0.55, F$ test $p<0.0001$, df $=67$ ).
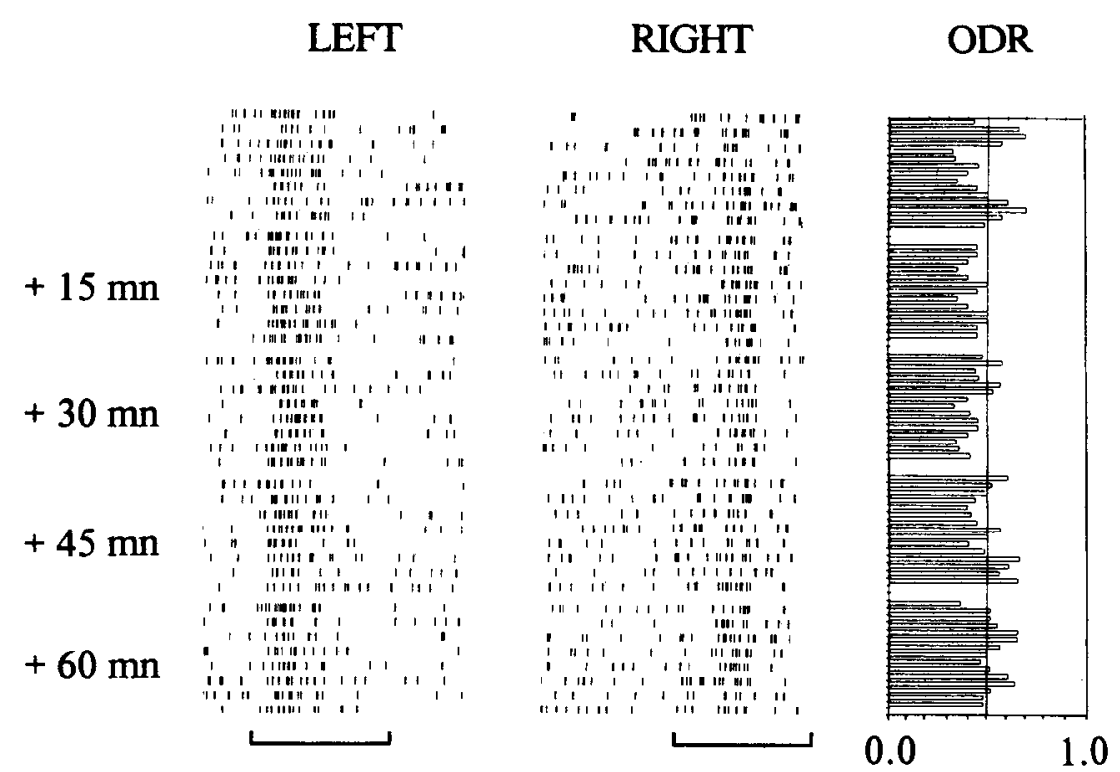

$b$
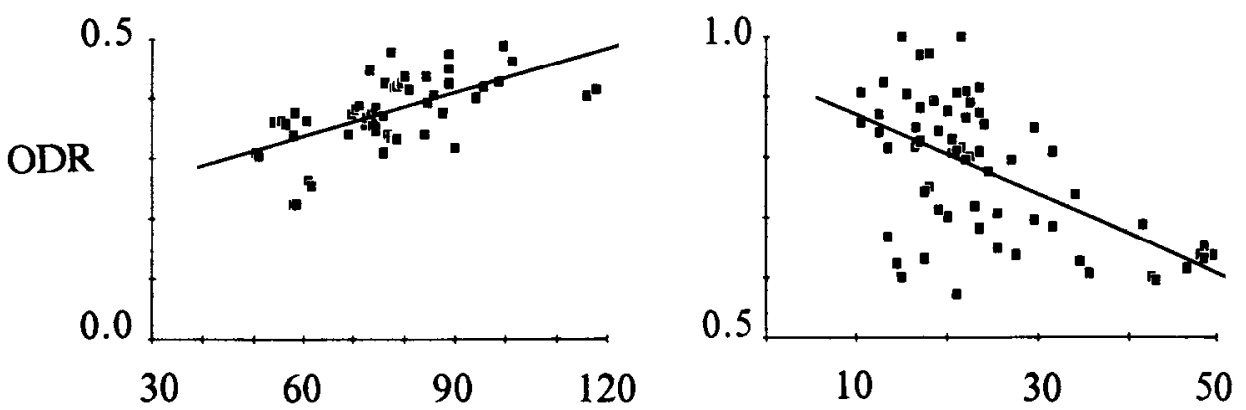

MEAN VISUAL ACTIVITY

\section{Iontophoretically induced variability of ocular dominance}

A second control assessed the degree to which ocular dominance was independent of the iontophoretic current applied permanently through the recording microelectrode. For 22 cells $(4$ in the kitten and 18 in the adult), stability of the ODR was quantified at different preset levels and polarities of iontophoretic current, ranging from $-15 \mathrm{nA}$ to $+10 \mathrm{nA}$ (which corresponded to the maximum current values used during pairing). The same data were used to look for a possible correlation between ocular dominance and the mean level of firing of the cell. Figure $2 b$ shows, in two of the recorded cells, a significant shift in ODR toward more binocular values with increasing mean visual activity. A likely explanation is that depolarization of the cell by positive iontophoretic current may result in a saturation of the response through the dominant eye and/or unmasking of subliminal responses through the dominated eye. To avoid these nonspecific changes in ocular dominance, controls were performed before and after pairing at the same level of iontophoret- ic current (usually no retention current was applied through the microelectrode). In the few cases where a consecutive change in excitability was observed, however, additional controls were performed after pairing by adjusting the level of current to produce a level of mean excitability comparable to that before pairing. In all "modified" cells, ocular dominance appeared independent of the level of excitability during the initial control period.

\section{Modifications of ocular dominance induced by differential pairing}

Altogether, 43 pairing procedures were applied to 24 neurons recorded in animals from 5 weeks of age to adulthood, and a significant modification of ocular dominance could be demonstrated in 8 of these cells (33.3\%). In most modified cells (7 of 8 ), shifts in ocular dominance favored the reinforced eye $\left(\mathrm{S}^{+}\right)$ (Table 1).

Twenty-four differential pairing procedures were performed on 14 cells recorded in kitten area 17 . Three cells (21\%) showed 
Table 1. Results summary

\begin{tabular}{|c|c|c|c|c|}
\hline & \multicolumn{3}{|c|}{$\begin{array}{l}\text { Experiment } \\
\text { 1. Ocular dominance }\end{array}$} & \multirow{2}{*}{$\begin{array}{l}\text { 2. IOD } \\
\begin{array}{l}\text { Kitten } \\
<15 \text { weeks }\end{array}\end{array}$} \\
\hline & $\begin{array}{l}\text { Kitten } \\
<15 \text { weeks }\end{array}$ & $\begin{array}{l}\text { Adult } \\
>1 \text { year }\end{array}$ & Total & \\
\hline Number of cells & 19 & 35 & 54 & 27 \\
\hline Number of pairings & 24 & 19 & 43 & 20 \\
\hline Number of paired cells & 14 & 10 & 24 & 15 \\
\hline Number of modified cells (\%) & $3(21.4 \%)$ & $5(50 \%)$ & $8(33.3 \%)$ & $6(40 \%)$ \\
\hline Percentage in favor of $S^{\prime}$ & $100 \%$ & $80 \%$ & $87.5 \%$ & $67 \%$ \\
\hline
\end{tabular}

statistically significant changes in ocular dominance favoring the "reinforced" eye $\left(\mathrm{S}^{+}\right)$. A successful pairing procedure in a 7 -week-old normally reared kitten is presented in Figure $3 a$. This cell was submitted to five successive pairing procedures, and at least two control periods were interposed between each pairing (see summary in Fig. $3 b$ ). Before the fourth pairing, the cell remained dominated by the contralateral left eye at a stable level $(\mathrm{ODR}=0.35 \pm 0.10)$. Immediately after this latter pairing, during which a significant increase in left eye response and a significant decrease in right eye response were both imposed (see Fig. $3 a$ ), the cell showed a significant change in its ocular dominance in favor of the reinforced eye $(\mathrm{ODR}=0.66 \pm 0.07$; KS $p<0.006$ ). This effect was transient, and total extinction was observed $10 \mathrm{~min}$ after the end of the pairing procedure. Figure $3 b$ summarizes the relative effect of each pairing on ODR, and furthermore suggests a linear relationship $(r=0.82)$ between the induced change and the imposed change in ocular dominance during pairing (see Fig. $3 c$ ).

In addition to the finding in kitten visual cortex that repeated pairings could restore or even increase the effect induced by a first pairing procedure (see Fig. 4), it was also observed that a separate zone in the receptive field can be modified differentially if pairing is restricted to a subregion of the dynamic zone of discharge. Figure 4 illustrates the case of a cell recorded in a 4.5-week-old normally reared kitten. In the two pairing procedures, current pulses were applied during stimulation of the border of the receptive field and both resulted in a significant increase of the visual response through the reinforced eye. Remarkably, the second pairing effects were only present within the receptive field zone where a significant iontophoretic control of activity had been previously imposed ( $90 \%$ increase). The second zone of discharge of the paired receptive field, whose activation occurred systematically outside the iontophoretic action, as well as the response to stimulation through the other eye (which was not paired, i.e., $\mathbf{S}^{0}$ ) were unchanged. In conclusion, restriction of the effects to the receptive field area where pairing had been effective in modulating activity argues strongly in favor of the associative nature of the induced functional modifications.

Functional changes were not exclusive to young animals, and an unexpected potential to undergo plastic changes was found in the adult cortex (over 1 year of age) (see Table 1). Nineteen pairing procedures were performed on 10 cells recorded in normal adult cats. Five cells (50\%) showed a statistically significant change in ocular dominance, of which four favored the reinforced eye $\left(\mathbf{S}^{+}\right)$. The cell shown in Figure $5 a$, initially dominated by the right eye $(\mathrm{ODR}=0.32 \pm 0.01)$, became significantly more binocular (ODR $=0.44 \pm 0.01 ; \mathrm{KS} p<0.007$ ) after a first pairing procedure, during which response to left eye stimulation was reinforced and that to the right eye stimulation was reduced. This effect could not be amplified by a second pairing (not shown). This could suggest a saturation or limit to the changes that can be produced by repeating the same pairing procedure in adult cortex.

A similar proportion of successful pairings was found in kittens and adults $\left(\chi^{2} p>0.63\right)$, and no significant difference between these two age groups was found in the distributions of amplitude of ODR changes (KS $p>0.51$ ). However, ocular dominance modifications observed in the adult corresponded to a shift of one class in a five class scale (see Fig. $5 a, b$ ), while in kitten shifts could be of two classes, that is, a cell initially dominated by one eye became transiently dominated by the other eye (see Figs. 3a, 4).

Such long-term modifications in ocular dominance-lasting from 10 min to a few hours, and obtained after one or several differential pairing procedures-were never observed spontaneously. In $37.5 \%$ of cases these specific changes in ocular dominance were not accompanied by global changes in excitability. In the remaining cases, they were associated with global depression of spontaneous and visual activity $(25 \%)$, or increased excitability (37.5\%). However, the time course of both types of effects were uncorrelated, and similar changes $(56.25 \%)$ were also observed in cells unaffected by the pairing procedure. In conclusion, the observed modifications in excitability levels were uncorrelated with the occurrence of specific modifications in ocular dominance $\left(\chi^{2}=0.031 ; \mathrm{df}=1 ; p>0.89\right)$. This suggests that these changes in spontaneous activity were epiphenomena of the pairing procedure.

The iontophoretic control of the postsynaptic activity during pairing was crucial in the induction of functional modifications. Among the eight cells for which iontophoretic current had no effect on the activity, none showed any change in ocular dominance. Conversely, 8 of the 16 cells for which a significant control of the postsynaptic activity was achieved during pairing showed a significantly modified ocular dominance after pairing. These results indicate that an effective increase or decrease (or both) of the spiking activity of the postsynaptic neuron appears to be a necessary requisite. The minimum number of associations required to induce a significant effect was 9 (first pairing in Fig. 4), but for most cells 80 paired stimulations of both eyes were performed before proceeding to a new control.

The simultaneous use of two kinds of iontophoretic action, that is, current and ionic ejection, makes one wonder if the observed effects were systematically related to the $\mathrm{K}^{+}$ejection or simply resulted from imposition of different levels of covariance between pre- and postsynaptic activity. Two arguments 
Figure 3. Ocular dominance changes in kitten. This cell was recorded for 2 hr $35 \mathrm{~min}$ in a 7 -week-old normally reared kitten. Five differential pairing procedures were applied during which stimulation of the left eye ( $L E F T$ col$u m n$ in $a$ ) was paired with a negative current of $15 \mathrm{nA}$ and that of the right eye (RIGHT column in $a$ ) was paired with a positive current of $10 \mathrm{nA}$. $a$, Fourth pairing procedure. Open histograms correspond to PSTHs synchronized with the onset of the sweep of the moving visual stimulus [calibration: vertical, 10 action potentials (a.p.)/sec; horizontal, $1.5^{\circ}$ and $1 \mathrm{sec}$ in the control situation (no current applied). Onset and $P S T H s$ ) are indicated by solid triangles. lution of the ODR corresponding to the sequential analysis of each row of PSTHs before $(C)$, during $(P)$, and after pairing $(+10 \mathrm{mn})$. The solid line represents the mean value of ODR during the initial control period $(C)$. Statistical analysis shows (1) that ocular dominance that was initially in favor of $\mathrm{S}^{-}$ ward $\mathrm{S}^{+}(\mathrm{KS} p<0.01)$, and (2) that it (arrow). $b$, Temporal evolution on a 155 min period of the mean values $(+S D)$ of ODR for successive control (open bars) and pairing (solid bars) situations. Each open bar is the mean ODR calculated on 20 successive stimulations of each eye during control periods. Solid bars correspond to the mean ODR calculated on 40 successive stimulations of each eye during pairing periods. Significance levels of the KolmogorovSmirnov test are given when comparing series of values observed before and during pairing, or before and after pairing ( $n s$, nonsignificant; * $p<0.01$; ${ }^{* *}$, $p<0.005) . c$, Correlation between the induced change in ODR ("after" minus "before" pairing) and the imposed change in ODR ("during" minus "before" pairing), for each of the pairing procedures. The more effective the pairing was, the larger was the observed offset of ionophoresis (middle row, solid To the right is given the temporal evoshifted significantly after pairing toreturncd to its initial value $10 \mathrm{~min}$ later change in ocular dominance $(r=+0.82)$.

$\mathbf{a}$

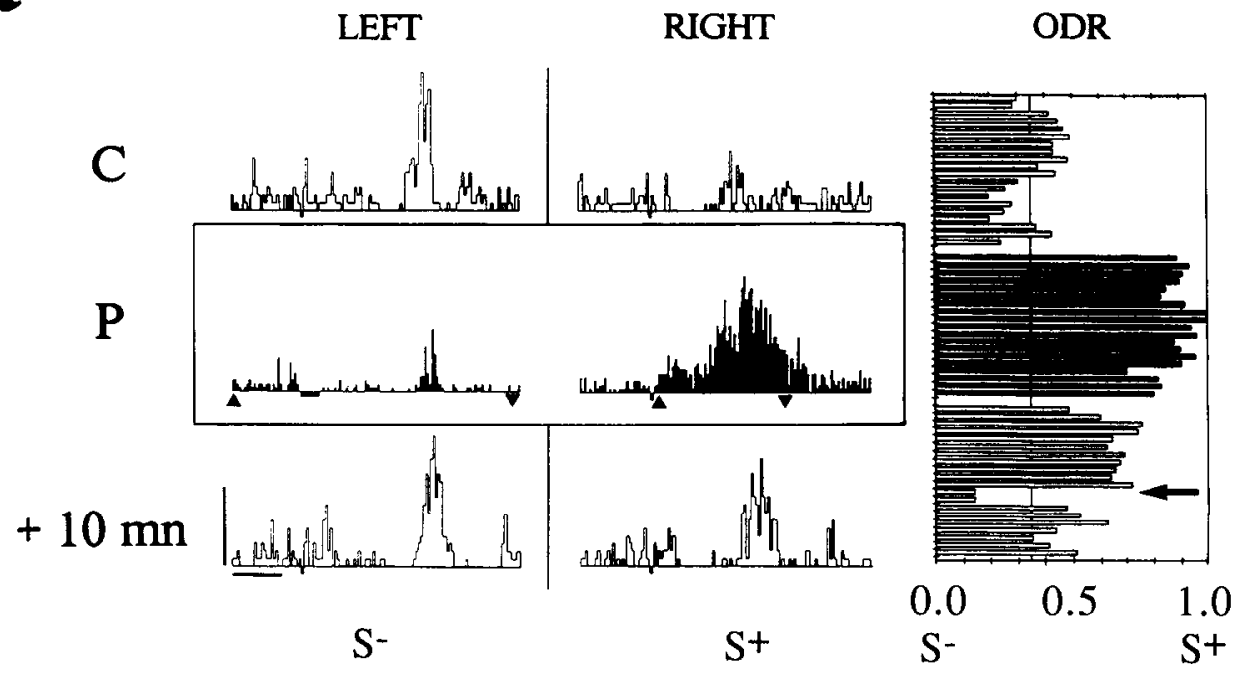

b
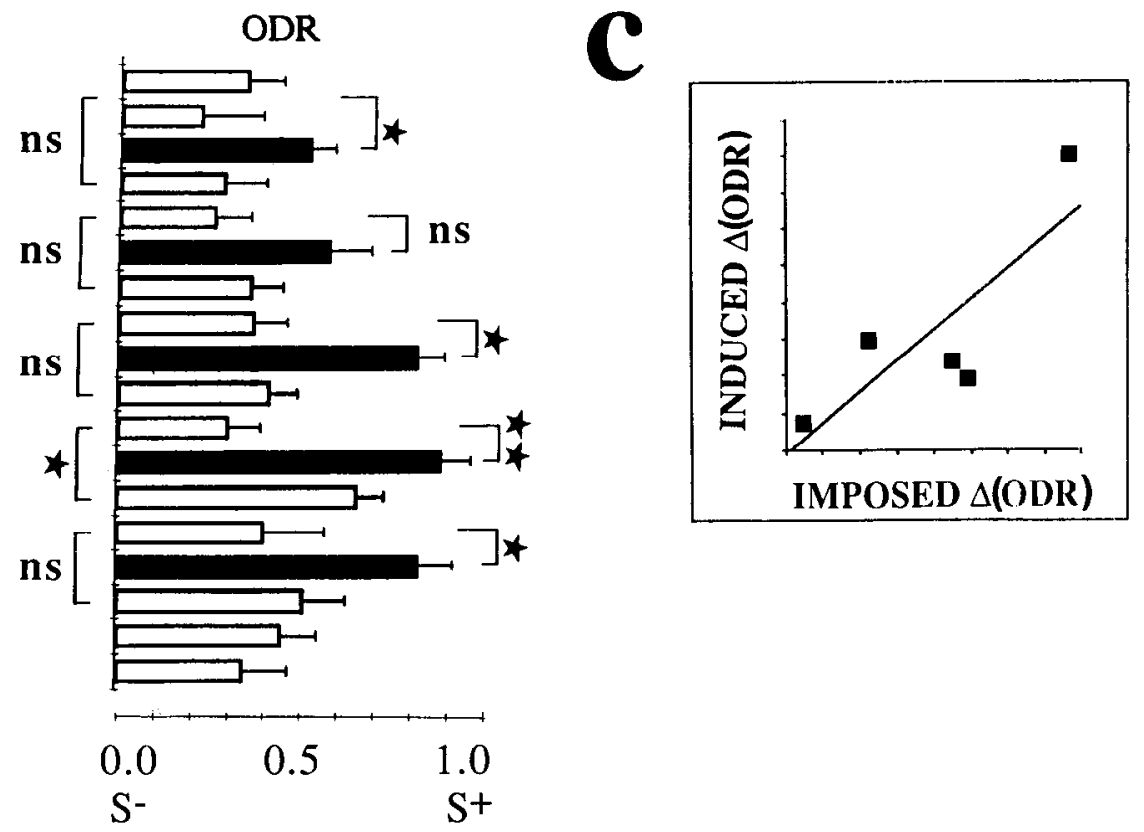

favor this latter possibility (see Discussion in Frégnac et al., 1992): first, the association of a visual stimulus with a negative iontophoretic current (i.e., without ejection of $\mathrm{K}^{+}$ions) can induce lasting changes in the absolute level of response of the cell through one eye (see Fig. 7); and second, in one case (Fig. 6) the pairing resulted in a change in ocular dominance in favor of the eye associated with a decreased level of activity during pairing $\left(\mathrm{S}^{-}\right)$despite the fact that $\mathrm{K}^{+}$ions were ejected when presenting the stimulus through the other eye $\left(\mathbf{S}^{+}\right)$. In this particular cell the functional change can still be explained on the basis of the covariance levels imposed for subzones of the receptive field (see Fig. 6 caption).

Ocular dominance changes were only found in cells that were initially binocular. However, the success rate of the pairing pro- cedure was found to be independent of the initial degree of imbalance between the two eyes. Thirty-six percent of cells ( 5 of 14) showing an ocular preference, that is, belonging to class 2 or 4 in a five class scale ocular dominance histogram, and $33 \%$ of truly binocular cells ( 2 of 6 ), that is, belonging to class 3 , were modified. In contrast, no significant change was obtained in four neurons responding initially through only one eye. Despite repeated pairing procedures when iontophoretic positive current was applied during the visual stimulation of the putative receptive field of the silent eye-estimated from the position of that of the last binocular cell recorded in the same track-these cells remained monocularly activated (Fig. 7).

Although moving stimuli appeared to be more efficient than static ones in the activation of cortical cells, particularly in youn- 


\section{LEFT}

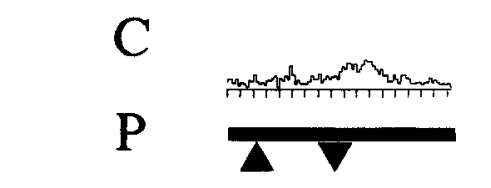

$+10 \mathrm{mn}$

$+60 \mathrm{mn}$

$+65 \mathrm{mn}$
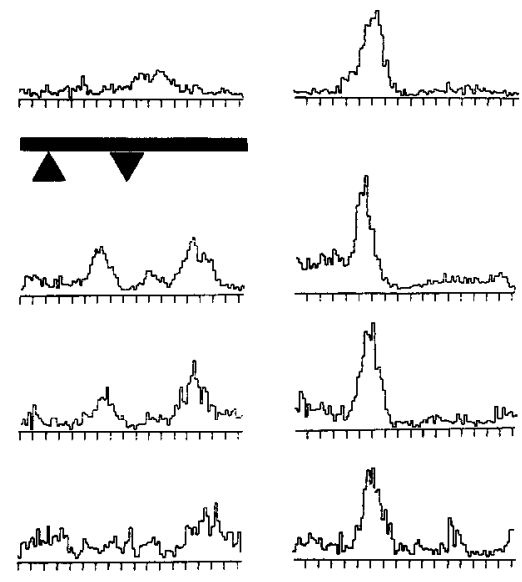

P

$+10 \mathrm{mn}$
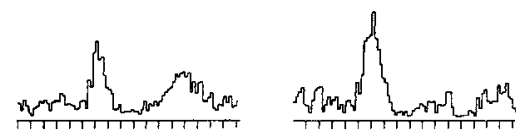

$+30 \mathrm{mn}$
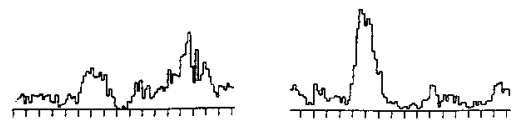

$+110 \mathrm{mn}$
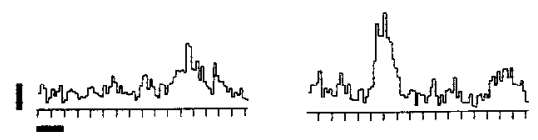

$\mathbf{S}^{+}$
ODR

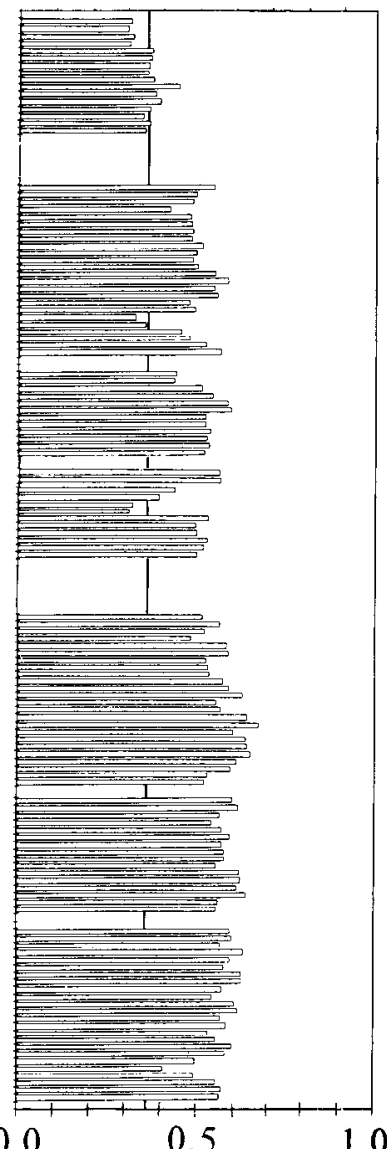

0.0

$\mathrm{S}^{\circ}$
I
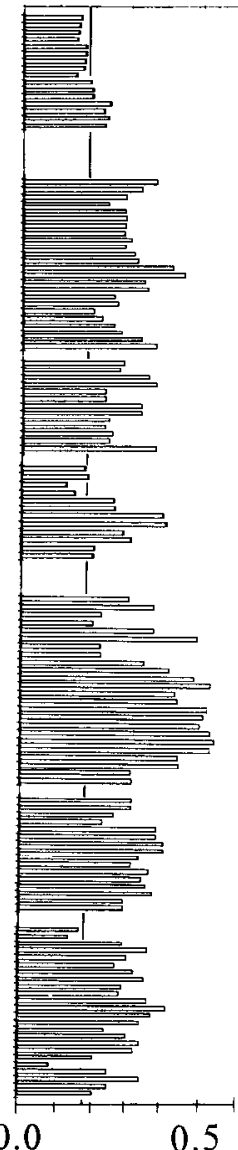

0.0

$\mathrm{S}^{+} \mathrm{S}^{\circ}$
E

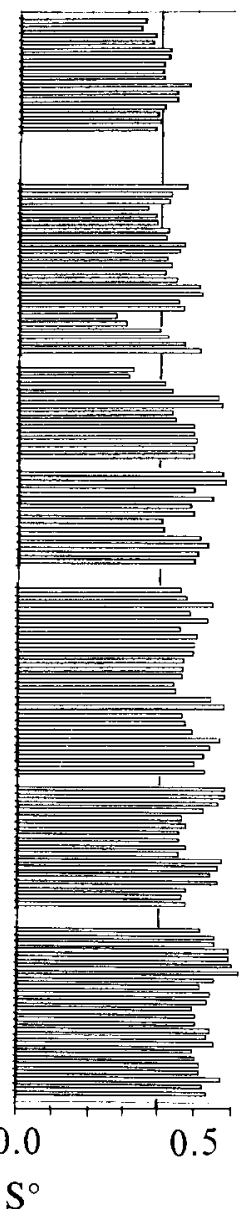

Figure 4. Ocular dominance changes at the peak of the critical period: recordings from a 4.5 -week-old kitten reared normally. Two identical pairing procedures induced a similar shift in ocular dominance in favor of the eye paired with the high level of activity (left eye; $\mathrm{S}^{+},+5 \mathrm{nA} ;$ right eye; $\mathrm{S}^{0}$, no current applied). This effect lasted for several tens of minutes. PSTHS represent visual responses to stimulation of the left eye (LEFT column) and the right eye (RIGHT column), before and after two pairing periods (black lines). The increase of the visual response to the left eye $(+40 \%)$, imposed during the first pairing (nine $\mathrm{S}^{+}$trials) and limitcd within a restrictcd zonc of the receptive field (indicated by solid triangles), was retained for $60 \mathrm{~min}(\mathrm{KS} p<0.002)$. After total extinction, this effect was reinstated following a second pairing procedure (imposing a $90 \%$ increase in firing during $24 \mathrm{~S}^{+}$trials), and this second enhancement was retained for a further $100 \mathrm{~min}$ (KS $p<0.032$ ). The response to stimulation of the right eye was unchanged. Calibration: vertical, $10 \mathrm{a.p.} / \mathrm{sec}$; horizontal, $1 \mathrm{sec}$ and $1.5^{\circ}$. In the right panel, the corresponding simultaneous temporal evolution of three ocular dominance ratios $(O D R, I, E)$ are plotted from top to bottom. The solid lines represent the mean control value of each of these ratios. After the first pairing, ODR shifts significantly toward $\mathrm{S}^{+}$(ODR before pairing, $0.36 \pm 0.04$; ODR after pairing, $0.50 \pm$ $0.04 ; \mathrm{KS} p<0.004)$. To assess if this effect was restricted to the region of the left eye receptive field (RF) where an iontophoretic control of discharge had been effective, partial ODR established on the paired $\left[I ; \mathrm{ODR}_{\mathrm{I}}=\mathrm{I} /\left(\mathrm{I}+\mathrm{S}^{0}\right)\right]$ and the contiguous unpaired $\left[E ; \mathrm{ODR} \mathrm{E}_{\mathrm{E}}=\mathrm{E} /\left(\mathrm{E}+\mathrm{S}^{0}\right)\right]$ zones of the $R F$ were calculated before, during, and after each pairing. $O D R_{1}$ ratios significantly increased following the associative procedures (ODR $R_{1}$ before first pairing, $0.19 \pm 0.06 ; \mathrm{ODR}_{\mathrm{I}}$ after first pairing, $0.30 \pm 0.08 ; \mathrm{KS} p<0.002 ; \mathrm{ODR}_{\mathrm{I}}$ before second pairing, $0.24 \pm 0.11 ; \mathrm{ODR}_{\mathrm{I}}$ after second pairing, $0.39 \pm 0.12 ; \mathrm{KS} p<0.03$ ), whereas $\mathrm{ODR}_{\mathrm{E}}$ ratios established for corresponding periods remained unchanged (ODR $\mathrm{E}_{\mathrm{E}}$ before first pairing, $0.40 \pm 0.05 ; \mathrm{ODR}_{\mathrm{E}}$ after first pairing, $0.42 \pm 0.08 ; \mathrm{KS} p>0.15 ; \mathrm{ODR}_{\mathrm{E}}$ before second pairing, $0.48 \pm 0.07 ; \mathrm{ODR}_{\mathrm{t}}$ after second pairing, $0.49 \pm$ $0.06 ; \mathrm{KS} p>0.14)$.

ger kittens, a study of the receptive field organization using stationary stimuli was performed quantitatively in some cases. In 10 out of the 24 cells submitted to at least one pairing procedure, the overlap of ON and OFF subregions and receptive field dimensions was determined. Six cells were classified as simple and four as complex following Hubel and Wiesel's initial classification (1962). Quantitatively measured responses to moving slits following the criteria used by Pettigrew et al. (1968) corroborated the static classification. Three of six cells classified as simple showed modifications in ocular dominance, while only one of the four complex cells was modified. A second classification was performed on 15 cells [ 8 of the 10 cells classified as simple or complex (see above) were included in this sample] using the criteria proposed by Leventhal and Hirsch (1980), who distinguished between small area slow (SAS), large area slow (LAS), and fast (F) cells. Five out of the eight cells classified as SAS $(62.5 \%)$ and only two out of the seven cells classified as LAS (28.5\%) showed a significant modification of ocular dominance. From this small sample, there is some evidence that simple or SAS cells could be more easily modified than complex or LAS cells (see Orban, 1984, for the details of these classification schemes). This could be explained by the fact that the former type of neuron more frequently receives direct geniculate afferents from each eye. Separate activation of distinct sets of 
$\mathbf{a}$

Figure 5. Ocular dominance changes in the adult. $a, A$ cell, initially dominated by the right eye and recorded in an adult cat over 1 year of age, was submitted to two pairing procedures. During pairing $(P$, solid histograms), the left eye stimulation ( $L E F T$ column) was associated with a positive current $(+5$ $\mathrm{nA})$, and the right eye stimulation (RIGHT column) was paired with a negative current $(-10 \mathrm{nA})$, producing a significant reduction of the visual response. Following the first pairing, the cell became more binocular. The mean ODR (right) for the initial control period shifted toward $\mathrm{S}^{+}$during pairing (mainly because of the negative current action during $S$ ), and this effect was significantly maintained $10 \mathrm{~min}$ afterward (KS $p<0.007)$. A second pairing procedure (not shown) did not increase this effect any further. $b$. Another cell, recorded in an adult cat, was initially strongly dominated by the left eye. Forty pairings imposing (through both $S$. and $S^{-}$iontophoretic actions) a significant shift in ocular dominance toward the nondominant eye $(P$, solid histograms; KS $p<0.004$ ) were sufficient to induce a persistent increased responsiveness in favor of the "reinforced" eye. Note that computation of the ODRs presented to the right (ODR before pairing, $0.11 \pm 0.01$; ODR after pairing, $0.42 \pm 0.03 ; \mathrm{KS} p<0.01$ ), which uscs visual responses corrected from spontaneous activity levels, takes into account the transient increase in spontaneous activity. Extinction of the effect was observed $20 \mathrm{~min}$ later $(r=-0.615$; $\mathrm{df}=27 ; F=15.85 ; p<0.001)$. Calibration: vertical, 10 a.p./sec; horizontal, $1 \mathrm{sec}$ and $1.5^{\circ}$.

synapses respectively associated with the $S^{-}$and the $S^{\prime}$ stimuli should be more efficiently achieved at the level of first-order geniculocortical terminals than after relay by binocular interneurons.

\section{Typology and time course of ocular dominance changes}

In $75 \%$ of the cases, ocular dominance changes resulted from a differential change in the amplitude of the initial response elicited by both eyes. In the remaining $25 \%$ of the cases, the effect corresponded to a reorganization of the temporal structure of the poststimulus time histograms (PSTHs), such as a change in the amplitude of different subzones within a multimodal receptive field (see Fig. 6) or in the size of the receptive field, unmasking initially subliminal zones (see Fig. 4).
LEFT RIGHT ODR
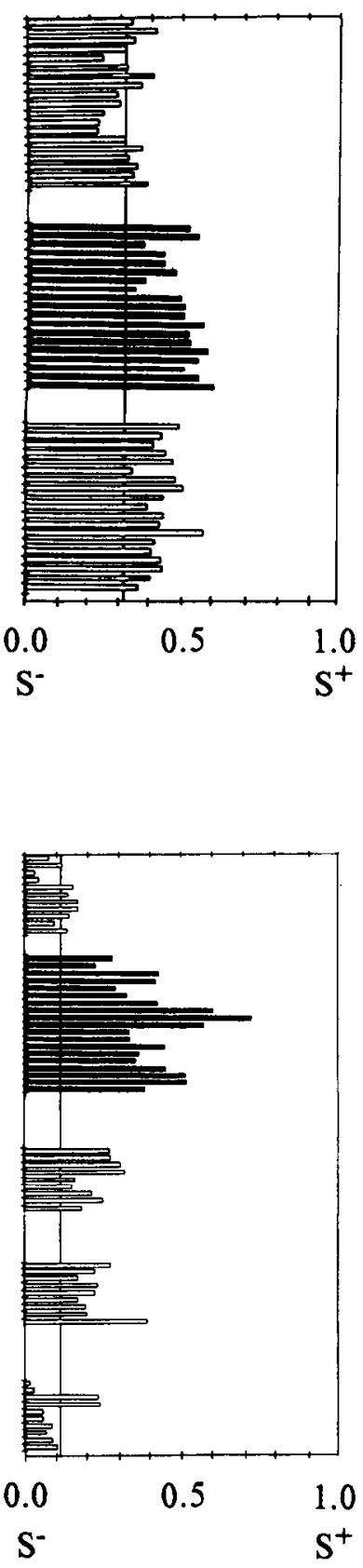

A feature common to all the observed modifications is that they developed immediatcly after the end of pairing. No delayed effect was found, as occasionally observed for the orientation selectivity protocol when pseudopairing was interleaved before pairing (see Frégnac et al., 1992). The time course of modifications differed from cell to cell. The shortest changes lasted about 10 min (see Fig. 3), but in some cases the effect was present throughout the recording and no extinction was observed (see Fig. 6). In five out of the eight modifed cells the ODR returned to the initial control value within 100 min after pairing (see Fig. 4). One cannot exclude that such extinction of the observed effects could result from the omission of the iontophoretic current (omission of the reinforcement) during the control period following pairing, and not from a spontaneous forgetting mech- 

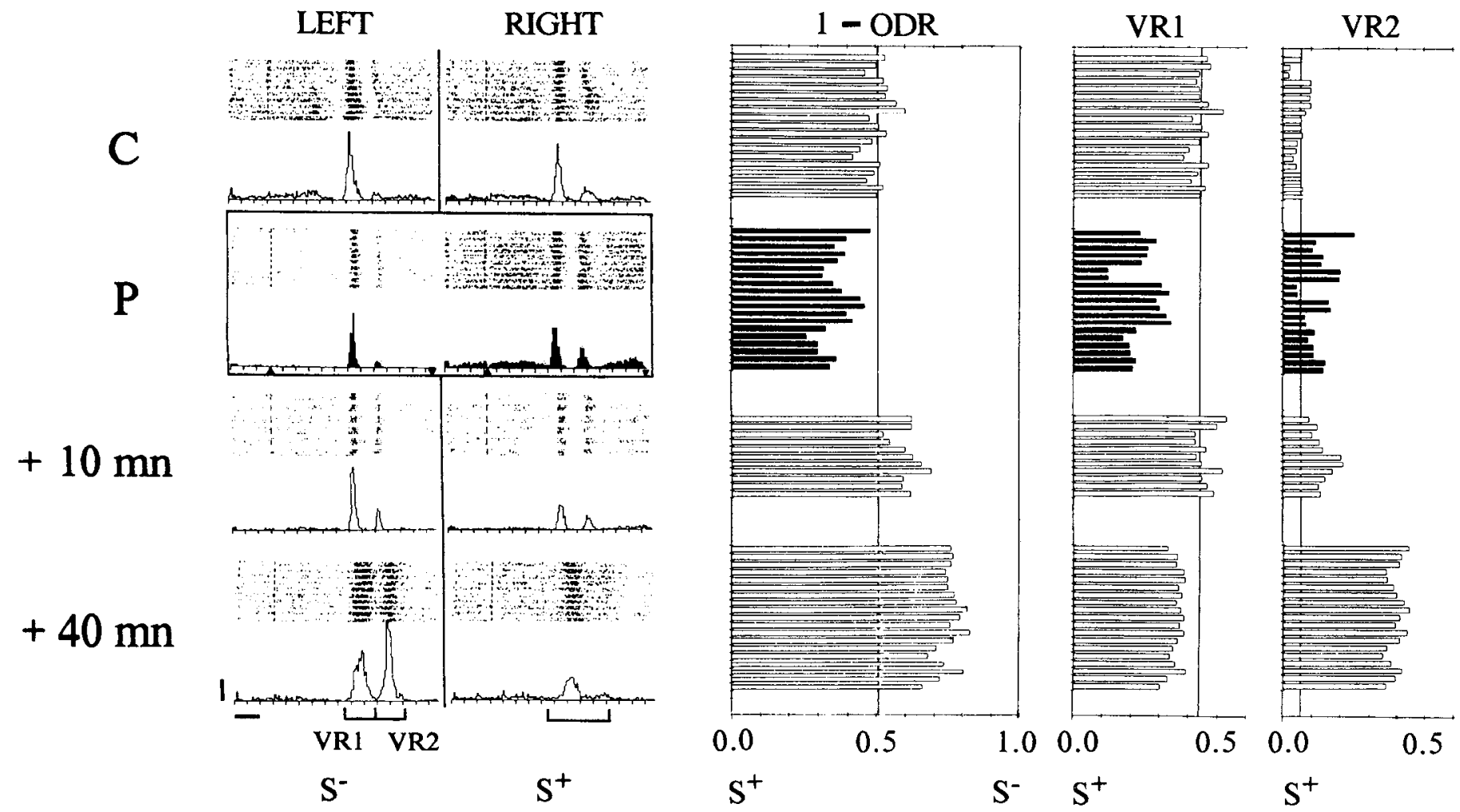

Figure 6. Ocular dominance change in favor of $\mathrm{S}^{-}$: binocular cell recorded in an adult cat over 1 year of age. The study of postsynaptic activity during iontophoresis indicates actions paradoxically opposite to those that would normally be expected from the differential pairing procedure: for $\mathrm{S}^{+}$, a decreased visual response and a relative increase in the spontaneous activity were observed; in contrast, during $\mathrm{S}^{-}$, a total blockade of the spontaneous activity was observed with a concomitant partial reduction of the visual response. This pairing resulted in a shift in favor of the eye associated to a negative current. PSTHs and dot displays give the visual response to the stimulation of the left eye (LEFT) and of the right eye $(R I G H T)$, before $(C)$, during $(P$, solid histograms), and after $(+10$ and $+40 \mathrm{~min})$ pairing. The onset of the visual stimulation is indicated by a vertical succession of points in the dot display. Calibration: vertical, $10 \mathrm{a} . \mathrm{p} . / \mathrm{sec}$; horizontal, $1 \mathrm{sec}$ or $1.5^{\circ}$. In the right panel, the temporal evolutions of three different ocular dominance ratios $(1-O D R, V R I, V R 2)$ computed from the different rows of PSTHs are plotted from top to bottom. ODR inspection shows that, in spite of a significant shift imposed during pairing toward $\mathrm{S}^{+}$(ODR before pairing, $0.49 \pm 0.01$; ODR during pairing, 0.63 $\pm 0.01 ; \mathrm{KS} p<0.01$ ), the ODR moved toward $\mathrm{S}^{-}$(ODR before pairing, $0.49 \pm 0.01$; ODR after pairing, $0.39 \pm 0.01 ; \mathrm{KS} p<0.01$ ) after pairing. However, this result can be reinterpreted by a more detailed analysis using partial ratios VRI and VR2. These ratios, corresponding to the contribution $R_{i}$ of each peak of response during $\mathrm{S}^{-}$(with $\left.\mathrm{S}^{-}=R_{1}+R_{2}\right)$, are given by the general formula VR $i=R_{i} /\left(R_{1}+R_{2}+\mathrm{S}^{+}\right)$, such that VR1 + VR2 = 1 - ODR (see brackets under the lower PSTHs). Both partial ODRs changed in opposite directions during pairing (VR1 toward $S^{+}$, from $0.44 \pm 0.01$ to $0.24 \pm 0.02 ; \mathrm{KS} p<0.001 ; \mathrm{VR} 2$ toward $\mathrm{S}^{-}$, from $0.07 \pm 0.01$ to $0.13 \pm 0.01 ; \mathrm{KS} p<0.01$ ). While no significant change from initial control values was observed $10 \mathrm{~min}$ after pairing for VRl (VR1 before pairing, $0.44 \pm 0.01$; VRl at $+10 \mathrm{~min}, 0.47 \pm 0.01$; KS $p>0.2$ ), VR2 values remained following pairing significantly shifted toward $S^{-}(\mathrm{VR} 2$ before pairing, $0.07 \pm 0.01 ; \mathrm{VR} 2$ at $+10 \mathrm{~min}, 0.15+0.01 ; \mathrm{KS} p<$ 0.008 ). Forty minutes later, a shift in VR1 toward $S^{+}$was observed (VR1, $0.44 \pm 0.01$; VR 1 at +40 min, $0.35 \pm 0.01 ;$ KS $p<0.002$ ) together with a reinforcement of the effect for VR2 (VR2 before paring, $0.07 \pm 0.01$; VR2 at $+40 \mathrm{~min}, 0.40 \pm 0.01$; KS $p<0.001$ ). Consequently, the global shift in ODR toward $\mathrm{S}^{-}$can be predicted from that imposed during pairing in the subzone VR2. Moreover, the long-term effects observed for each partial ratio are similar to those imposed during pairing (i.e., toward $S^{+}$for VR1 and toward $S^{-}$for VR2).

anism, as it has been suggested in other cortical areas (Diamond and Weinberger, 1986).

\section{Discussion}

This experiment demonstrates that an exogenous control of postsynaptic activity concurrent with an alternating monocular visual stimulation can induce long-term changés in ocular dominance during the time of recording of individual visual cells in area 17 of the paralyzed and anesthetized animal. In all but one case, the shift in ocular dominance favored the reinforced eye. These "acute" effects were analogous to the functional modifications induced by a global manipulation of the visual environment and observed comparing over time chronic multiunit activity recorded from the same cortical locus (Mioche and Singer, 1989).

The level of plasticity found in the present study should be compared with previous attempts to induce changes in func- tional properties of individual visual cells in anesthetized and paralyzed kittens, by the sole modulation of afferent retinal activity, without external reinforcement or suppression of the cell's response. Pettigrew et al. (1973) showed that repetitive visual stimulation of one eye already giving a suprathreshold response induced a weak change in responsiveness in favor of the stimulated eye in a limited number of cells (4 out of 60 ), but the use of noninterleaved protocols and the absence of study of intrinsic variability make interpretation difficult. More convincing evidence for acute changes in binocularity was provided by Kasamatsu (1976), who reported a long-term change in ocularity after total blockade of transmission of input from one eye following local application of an anesthetic to its optic nerve. The loss of responsiveness through the silenced eye persisted beyond the duration of the local anesthesia, suggesting a longterm decrease in synaptic efficacy.

To overcome the freezing of functional plasticity generally 
Figure 7. Depression of visual response in a monocular cell: recordings of a monocular cell in a 7-week-old reared normally kitten. During the two pairings ( $P$, solid histograms), the visual response of the responsive eye ( $L E F T)$ was significantly reduced to a "low" level by application of a $-2 \mathrm{nA}$ current, and the activity of the initially unresponsive eye ( $R I G H T)$ was clamped to a "high" level (with a +5.5 to $+9.0 \mathrm{nA}$ current) during presentation of a visual stimulus within the putative receptive field. In the right panel, the simultaneous temporal evolutions of mean visual activities through the active and the silent eye (in a.p./sweep) during the control and pairing periods are plotted from top to bottom. Although a statistically significant reduction of the already present visual response for $S^{-}$ (mean visual response before pairing, $5.4 \pm 0.4$; after pairing, $2.9 \pm 0.3 ; \mathrm{KS}$ $p<0.047$ ) was observed after the first pairing, no de novo response was created for $\mathrm{S}^{+}$in spite of a very effective control of activity during iontophoresis (see first and second pairing). Similar significant reductions of the absolute level of response to $S^{-}$and the lack of a response reinstated for $\mathrm{S}^{+}$were replicated in another monocular cell (not shown).

observed in the anesthetized and paralyzed preparation, associative protocols combining retinal and extraretinal stimulations have already been used, and significant changes in ocular dominance of single cells have been reported during the time of recording in a limited number of studies (Frégnac and Bienenstock, 1981; Tsumoto and Freeman, 1981). In such experiments, extraretinal stimulation can be thought of as a factor controlling the changes in the covariance between the afferent visual message and the postsynaptic response. Extraretinal control of activation indeed seems necessary to induce functional modifications (Von der Malsburg, 1973; Bienenstock et al., 1982). This requirement might be fulfilled more easily in the alert animal (see Mioche and Singer, 1989), when normal visuomotor experience activating extraretinal signals and attention processes appears to gate visual cortical plasticity (Buisseret et al., 1978; Trotter et al,, 1983).

Our iontophoretic protocol seems, accordingly, adequate in mimicking at the recording site the action of a nonretinal "supervisor." Similar forced changes in ocular dominance of single cells have been recently reported (Greuel et al., 1988) using a more pharmacologically elaborate version of our original procedure. The presentation of a stimulus of fixed ocularity was associated with the combined juxtacellular application of noradrenaline, $\mathrm{ACh}$, glutamate, and/or NMDA. The rate of success of the pairing procedure was independent of the drug combination, which probably indicates a common control mechanism of plasticity for all these drugs. Interestingly, $80 \%$ of changes favored the stimulus paired with the gating substances, which were reported for most of them to have mainly a facilitatory effect on the postsynaptic activity.

\section{Ocular dominance plasticity in the adult}

Our paradigm was used in animals older than 4 weeks of age and therefore concerns a system where the anatomical segre-
RIGHT

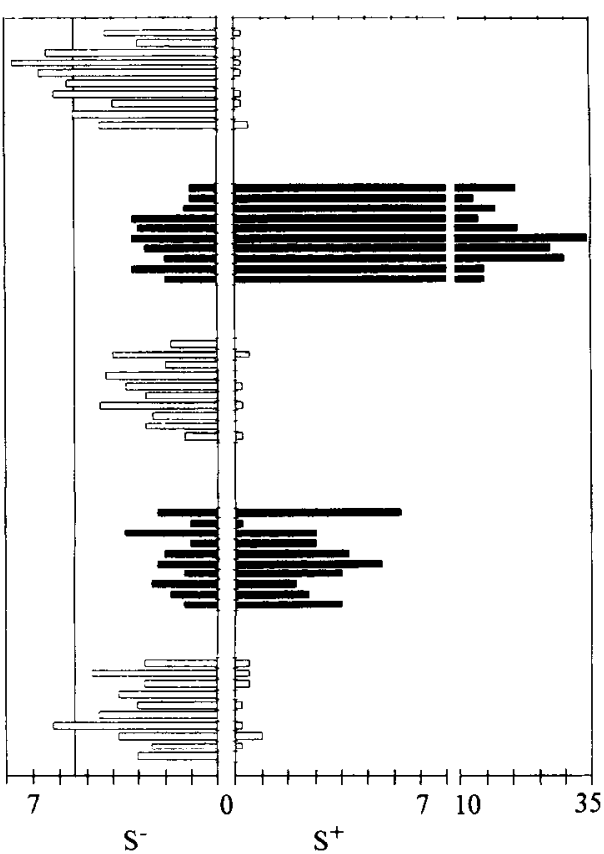

gation of the geniculate afferents from both eyes has ended (I eVay et al., 1978). Consequently, cortical cells receiving separate inputs from both eyes, and which represent a likely locus for the activation of mechanisms of competition, are present in both kittens and adults. Note that cortical cells already receiving binocular afferents are not thought to be modifiable since the same group of synapses will be activated during both positive and negative current periods.

Although this anatomical substratum for synaptic competition is still present in the adult cortex, the finding of ocular dominance changes in cats over 1 year of age may appear unexpected from classical deprivation studies. Our supervised learning procedure demonstrates that adult cortical cells still retain a potential to undergo plastic changes. However, it is possible that our artificial iontophoretic technique uncovers a plasticity process not normally activated in the adult. This remark also applies to the findings of Kasamatsu et al. (1985), who induced changes in global binocularity in 2-year-old cat visual cortex by associating monocular vision with electrical stimulation of the locus coeruleus. Our data nevertheless support the conclusion that visual cortex is able under forced coactivity conditions to express a capacity for neural adaptation similar to that already reported in other primary sensory cortices (Merzenich et al., 1984; Diamond and Weinberger, 1986; see also Gilbert and Wiesel, 1991).

\section{Experiment 2: Plasticity of Interocular Orientation Disparity}

The goal of this second experiment was to demonstrate the induction of activity-dependent modifications in IOD preference or IOD selectivity while recording from a single cell, analogous to the changes in cortical binocular integration shown by Shinkman and colleagues using a population analysis strategy. We developed a cellular paradigm in which, under a binocular 
viewing condition, the response of the recorded cell to the dichoptic presentation of two monocular oriented stimuli-corresponding to a fixed orientation disparity configuration - was artificially increased, and that for an opposite orientation disparity was artificially decreased or blocked. This differential control of the postsynaptic response was intended to produce competitive changes in the selectivity profile of the IOD tuning curve in favor of the disparity associated with increased responsiveness. Additional information on the associative nature of the induced changes was gained by comparing modifications of the binocular responses (which were artificially modulated during the pairing procedure) with possible alterations of the monocular responses to each element of the dichoptic stimulus configuration. If binocular integration is somehow more complex than the linear summation of responses to monocular activation, and if induced changes are truly associative, one would expect the conditioning procedure to preferentially affect binocular processes active during pairing.

\section{Materials and Methods}

The surgical preparation of animals and the electrophysiological techniques were the same as in experiment 1 . Twelve normally reared kittens aged from 4 to 15 weeks were used.

Monocular and binocular visual stimulation. The receptive fields of the left and right eye were optically separated on the projection screen by Risley prisms placed in front of each eye. Quantitative determinations of monocular orientation tuning curves and of binocular IOD tuning curves were performed in the following way (see $\mathbf{M}$ and $\mathbf{B}$ protocols detailed in Fig. 1c).

(1) To follow the temporal evolution of each monocular response, orientation tuning curves were constructed by presenting in a pseudorandom order different orientations to one eye and the other in alternation. The preferred orientations derived from each initial control luning curve were then considered arbitrarily as the $0^{\circ}$ referencc orientation for each eye. Since our only concern was the determination of changes in IOD, our convention avoided the tedious measurement of cyclotorsion of the eyes due to the paralysis, which otherwise has to be taken in account to assess the absolute value of the differences between the preferred orientations for each eye.

(2) The tuning curves for IOD corresponded to at least three randomized binocular presentations of the following series of relative disparities: $0^{\circ},+16^{\circ},-16^{\circ},+45^{\circ},-45^{\circ},+90^{\circ},-90^{\circ}$, the convention being IOD $=$ left - right (tuning curve B in Fig. 1c). This was achieved by splitting the beam of a computer-controlled visual stimulator into two separate beams, one of them being transmitted through a variable rotational Dove prism. For nonzero disparities, the orientations presented to each eye were obtained by imposing symmetrical opposite rotations on each beam; $+16^{\circ}$, for example, corresponded to simultaneous stimulation of the left eye with a $+8^{\circ}$ stimulus and of the right eye with a $-8^{\circ}$ stimulus (away from the respective preferred orientation for each eye). The binocular IOD tuning curves were measured by changing the stimulus orientation while keeping all the other stimulation parameters identical for both eyes. This requirement was controlled systematically in order to avoid additional modulation of the binocular response due to interocular differences in the phase of stimulation of each receptive field (Bishop et al., 1971). The midsweep position of each monocular exploration during construction of the control monocular tuning curves was adjusted so as to optimize the overlap of each monocular PSTH among all orientations.

After establishing the monocular orientation tuning curves and the binocular orientation disparity tuning curve, a control study of the relative preference between the two disparities to be used later during the pairing procedure was made. This involved presenting-in the absence of any iontophoretic current-a sequence of two blocks of two monocular and one binocular stimuli repeated in alternation at least 10 times (see the two elementary sequences detailed below and Fig. 1c):

$\begin{array}{ccc}\text { MONOC } & \text { MONOC } & \text { BINOC } \\ +8^{\circ}(\mathrm{L}) & 8^{\circ}(\mathrm{R}) & +8^{\circ}(\mathrm{L}) \text { and }-8^{\circ}(\mathrm{R})\left(\mathrm{IOD}=+16^{\circ}\right) \\ -8^{\circ}(\mathrm{L}) & +8^{\circ}(\mathrm{R}) & -8^{\circ}(\mathrm{L}) \text { and }+8^{\circ}(\mathrm{R})\left(\mathrm{IOD}=-16^{\circ}\right)\end{array}$

During pairing (see $\mathrm{P}$ in Fig. $1 c$ ), this sequence was reduced to two blocks of three trials of binocular stimulation repeated at least 10 times, the three presentations of one disparity (e.g., $+16^{\circ}$ ) being associated with the application of a positive current $\left(\mathrm{S}^{+}\right)$, and the three presentations of the opposite disparity (e.g., $-16^{\circ}$ ) being paired with a retention current $\left(\mathrm{S}^{-}\right)$. Values of applied currents ranged from $-13 \mathrm{nA}$ (mean, $-10 \mathrm{nA}$ ) to $+25 \mathrm{nA}$ (mean, $+7 \mathrm{nA}$ ). After at least 30 pairings for each disparity, a new iterative control series without current, as well as the binocular IOD and the two monocular orientation tuning curves, were performed to assess possible changes in binocular interaction.

Data analysis. An index of relative orientation disparity preference, given by the normalized ratio of visual responses $\left[\mathrm{S}^{+} /\left(\mathrm{S}^{+}+\mathrm{S}^{-}\right)\right]$, was calculated on successive blocks of six trials during both controls and pairing periods, and the distributions of IOD values established before, during, and after pairing were compared statistically as in experiment 1 .

Additional analysis was performed in order (1) to study the generalization effects over disparities other than those presented during the pairing procedure, as well as (2) to determine if changes in the monocular responses were sufficient to explain the changes in the binocular interaction whenever such changes were observed. From the responses recorded during the construction of the monocular orientation tuning curves, an orientation disparity tuning curve was made by assuming that the recorded neuron is simply adding the information from each eye. This computed tuning curve (M) was compared with the experimentally observed binocular disparity tuning curve (B), both before and after pairing. Binocular interaction was assessed from the disparity dependent profile found in the difference between these two curves (B $\mathrm{M}$; see example in Fig. 11), and classified in one of six possible classes (namely, selective facilitation or occlusion for either the optimal or nonoptimal disparity, and facilitation or occlusion independent of the disparity). Finally, a seventh class included all the cells showing no binocular interaction, for which the binocular response was equal to the sum of the corresponding monocular responses for all the tested disparities. The effect of the pairing procedure on IOD selectivity was quantified for each type of tuning ( $\mathrm{M}$ and $\mathrm{B}$ ) by the computation for each disparity of the differences between normalized visual responses (area of tuning $=100 \%$ ) before and after pairing. The normalized difference obtained in this way characterizes the gain (positive value) or the loss (negative value) relative to each disparity (see Frégnac et al., 1992).

In addition to this analysis, the ocular dominance of the cell based on the comparison of the best responses obtained separately through cach cyc was measured before and after each pairing in order to infer whether the IOD modification resulted from a specific adaptation of binocular integration or from a change in the balance of the monocular responses.

\section{Results}

Twenty-seven visual cells were recorded in area 17 of 12 normally reared kittens of 4-15 weeks of age, among which 15 cells were submitted to 20 pairing procedures and 12 were used exclusively for the study of the temporal stability of orientation disparity selectivity (see Table 1). Initial characterization of both receptive fields and completion of the various control protocols required recording from a single cell for approximately $1 \mathrm{hr}$ before applying any pairing procedure. This severely reduced the number of opportunities where pairing could be completed before losing the cell. The mean time of recording of cells submitted to a pairing procedure was $2 \mathrm{hr} 40 \mathrm{~min}$. The temporal stability of the orientation disparity tuning curves and the temporal evolution of the relative preference ratio between the two disparities to be used in an ulterior pairing procedure were studied on all 27 cells. None showed any significant spontaneous variation, during the time of recording, in the preferred IOD, or in the type of binocular interaction (studied up to $110 \mathrm{~min}$ ).

A first example of modification of the orientation disparity selectivity profile is presented in Figures 8-10. This cell was recorded in a 65-d-old normally reared kitten. Four pairing procedures were performed during a $7 \mathrm{hr}$ recording period (Fig. 
B

I.O.D. TUNING

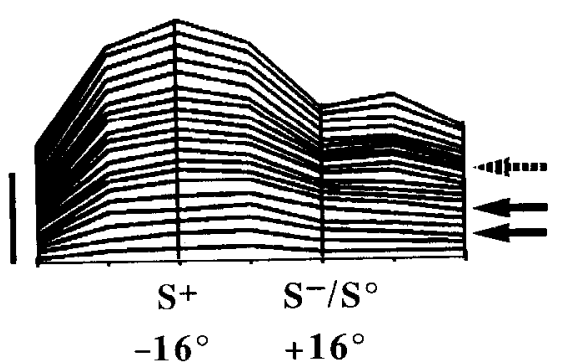

\section{MONOCULAR RESPONSES}

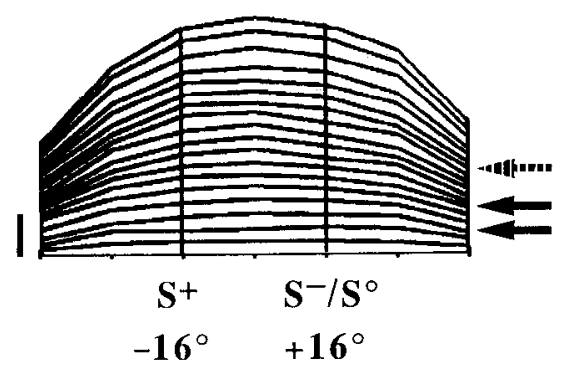

Figure 8. Modification of selectivity to IOD: recordings from a 9-weekold kitten reared normally. This binocular orientation biased cell was recorded for $7 \mathrm{hr} 5 \mathrm{~min}$. Three pairing procedures induced a shift in IOD selectivity in favor of the disparity paired with a positive iontophoretic current $\left(\mathrm{S}^{+},-16^{\circ}\right.$; first pairing, $+7 \mathrm{nA}$; second pairing, +11 $\mathrm{nA}$; third pairing, $+25 \mathrm{nA}$ ). A negative current was applied during the alternate presentation of the opposite disparity only in the first two pairings (solid arrows; $\mathrm{S}^{-},+16^{\circ}$; first pairing, $-7 \mathrm{nA}$; second pairing, $-9 \mathrm{nA}$ ). During the third pairing (striped arrow), no negative current was applied $\left(\mathrm{S}^{0}\right)$, since the response for this latter disparity became almost totally depressed following the first two pairings. $B$, Binocular IOD tuning curves in the control situation have been cumulated upward over time. The first three bottom traces correspond to the initial selectivity profile observed before any pairing, and the maximum response was obtained for a null IOD abscissa (corresponding to the pair of orientations respectively preferred through each eye). After three successive pairing procedures (arrows), the peak of selectivity shifted progressively toward the $S^{+}$disparity. A loss of responsiveness developed concurrently around the other disparity shown in alternation $\left(\mathrm{S}^{-}\right.$or $\left.\mathrm{S}^{0}\right)$. $M$, Cumulative theoretical IOD tuning curves-given by the sum of the responses of the cell to each monocular component of the dichoptic stimulus-have been computed for each corresponding binocular IOD curve. Note the remarkable temporal stability of the tuning profile, centered on the initial preference (zero disparity), and that of the relative responses for the $\mathrm{S}^{+}$and $\mathrm{S}^{-}$(or $\mathrm{S}^{0}$ ) disparities. Abscissa for $B$ and $M$, IOD values (from left to right): $-90^{\circ},-45^{\circ},-16^{\circ}\left(\mathrm{S}^{+}\right), 0^{\circ}$ (initial preference), $+16^{\circ}$ ( $\mathrm{S}^{-}$for the first two pairings, $\mathrm{S}^{\circ}$ for the third pairing), $+45^{\circ}$, and $+90^{\circ}$. Vertical calibration: 200 a.p.

8), the last one corresponding to an inversion of the orientation disparity associated with a high level of firing (reverse protocol in Fig. 9). The initial occlusion-which occurred for all disparities before the first pairing (compare ordinate scale in $\mathrm{M}$ and B in Fig. 8) - was reinforced after each of the first two pairings for the $S^{-}$disparity (i.e., $+16^{\circ}$ ). After the third pairing procedure, a selective facilitation appeared in addition for the $\mathrm{S}^{+}$disparity (i.e., $-16^{\circ}$ ). Consequently, the initial IOD preference for a null disparity shifted toward the disparity associated with a high level of discharge $\left(\mathrm{S}^{+}\right)$. The computation of normalized differ-

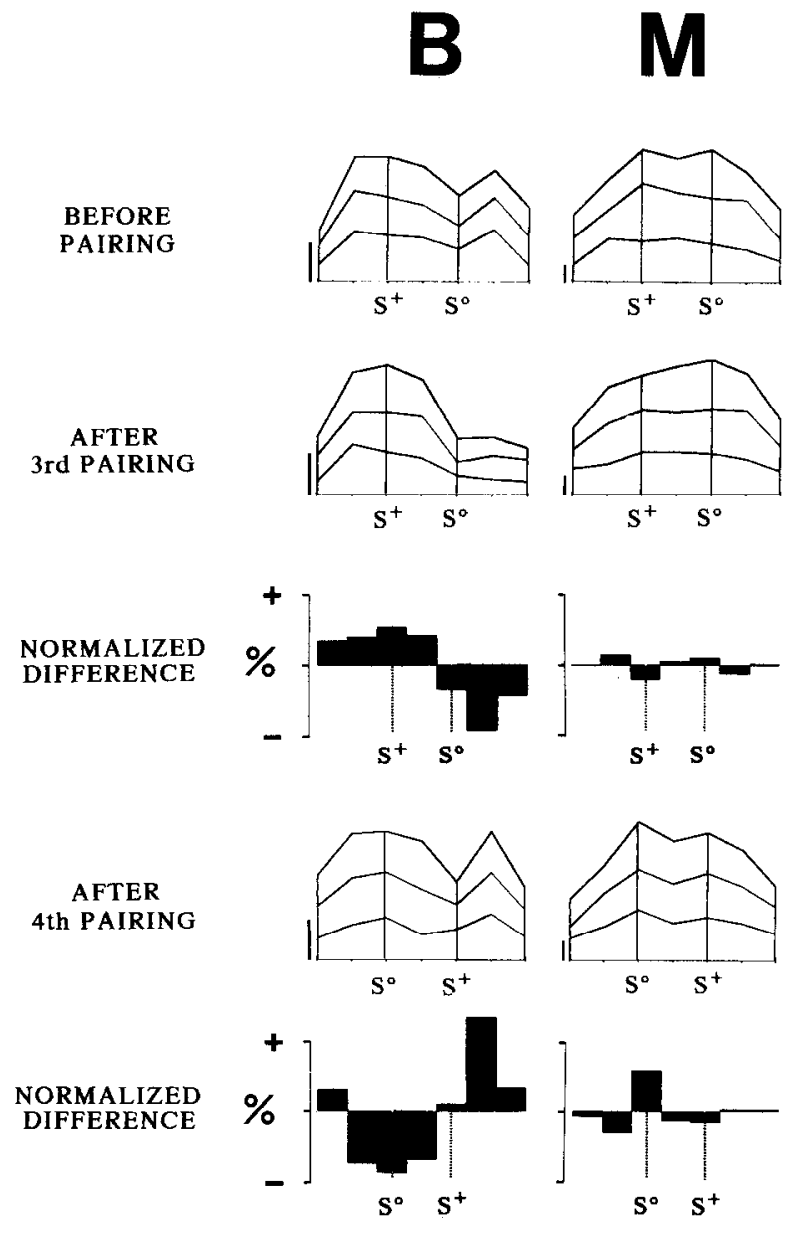

Figure 9. Reversibility of the effects of the pairing procedure (same cell as in Fig. 8). $B$, Cumulative tuning curves for IOD selectivity obtained during binocular stimulation, before and after the third pairing. The slight dip in the initial tuning profile for the $S^{n}$ disparity is due to the previous first two pairing procedures (illustrated in Fig. 8). This effect is further accentuated after the third pairing. After a fourth pairing procedure, where the $\mathrm{S}^{+}$and $\mathrm{S}^{\circ}$ disparities were inverted, the cell developed a tuning curve profile similar to that observed just before the third pairing. Relative gains and losses of response induced by each pairing as a function of disparity (represented by solid histograms) illustrate the reversibility of the effect. $M$, Cumulative IOD tuning curves computed from the sum of the corresponding monocular responses. The same normalized difference analysis applied to the theoretical tuning curves shows that no change was present in the monocular responses after the third pairing. The absence of significant monocular effects after the fourth inverse pairing confirms that changes in the IOD tuning profile were expressed only in the binocular viewing condition. Abscissa for tuning curves and normalized differences (from left to right): $-90^{\circ},-45^{\circ}$, $-16^{\circ}, 0^{\circ},+16^{\circ},+45^{\circ},+90^{\circ}$. Calibration: tuning curves, 20 a.p.; normalized differences, $\pm 5 \%$.

ences between the binocular responses (B) after and hefore the third pairing shows a selective gain for the $\mathrm{S}^{+}$and nearby disparities and a loss of selectivity for the $\mathrm{S}^{0}$ (previously $\mathrm{S}^{-}$; see Fig. 8 caption) and nearby disparities (Fig. 9, B). In contrast, a similar computation applied to the response predicted from the sum of the responses to each corresponding monocular component (M) indicates no modification (Fig. 9, M). Ocular dominance level, assessed from the comparison of the response to each eye, was unchanged, although a shift of the monocular preferred orientations was apparent after the first pairing procedure toward the respective orientations corresponding to the 
a

B

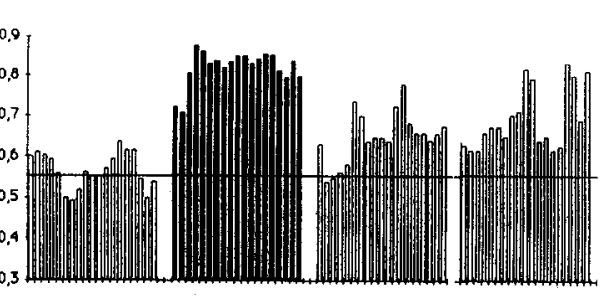

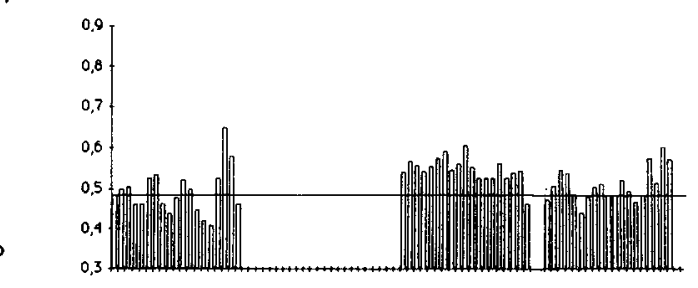

$\mathrm{S}^{+}$

M

$S^{\circ}$

$S^{+}$

$$
-16^{\circ}+16^{\circ}
$$

CONTROL
PAIRING
$+\quad 10 \mathrm{mn}$
$+110 \mathrm{mn}$
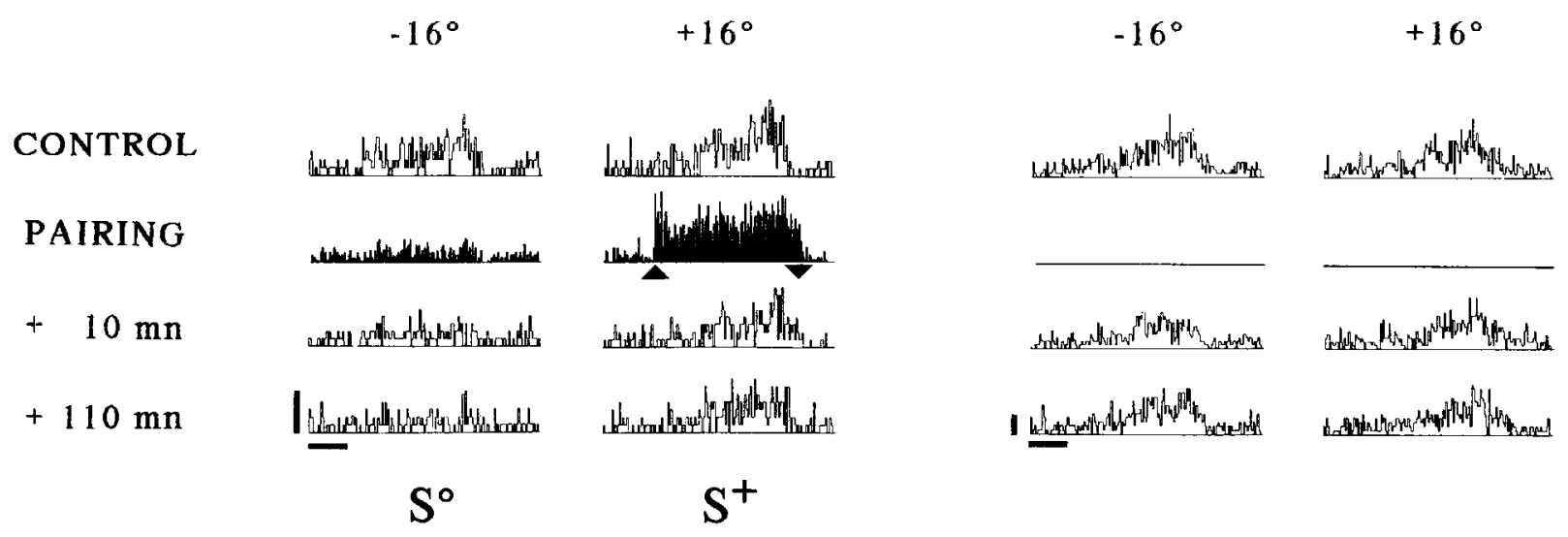

$\mathrm{b}$

Figure 10. Independence in the temporal evolution of monocular and binocular responses after pairing (same cell as in Figs. 8 and 9 , third pairing). $a$, IOD bias ratios - given by $\mathbf{S}^{+} /\left(\mathbf{S}^{+}+\mathbf{S}^{0}\right)$-calculated from the binocular $(B)$ and monocular $(M)$ responses before, during (solid bars), and 10 and 110 min after pairing. $B$, Binocular responses: the mean control value of the $\mathrm{IOD}_{\mathrm{B}}$ ratio is indicated by a solid line $(0.57 \pm 0.01)$. During pairing, a significant competitive advantage was imposed for the $\mathrm{S}^{+}$disparity $(0.82 \pm 0.01 ; \mathrm{KS} p<0.001)$. This resulted in a long-lasting shift in the relative IOD preference (at +10 min after pairing, $0.649 \pm 0.014 ; \mathrm{KS} p<0.012)$, still present 110 min afterward $(0.695 \pm 0.018 ; \mathrm{KS} p<0.005)$. The following inverse pairing detailed in the lower part of Figure 9 (IOD bias ratio during pairing, $0.374 \pm 0.005$; KS $p<0.001$ ) induccd a complctc reversal of the effect (KS $p<0.026)$. The final values of IOD bias ratio $(0.591 \pm 0.01$; not illustrated) were equal to those found before the third pairing. $M$, IOD bias ratios (IOD ) were calculated from the sum of the monocular responses. A transient increase in the mean control value (solid line, $0.493 \pm 0.013)$, was observed after pairing $(0.547 \pm 0.007 ; \mathrm{KS} p<0.017)$ and disappeared $110 \mathrm{~min}$ afterward $(0.501 \pm 0.009 ; \mathrm{KS} \mathrm{NS})$. This ratio was unmodified after the fourth inverse pairing (not shown; $0.492 \pm 0.008$; KS NS). $b$, PSTHs represent the visual responses for two different stimulus configurations $\left[-16^{\circ}\left(\mathbf{S}^{\circ}\right)\right.$ and $+16^{\circ}\left(\mathrm{S}^{+}\right)$columns] before $(C O N T R O L)$, during $(P A I R I N G)$, and 10 and 110 min after pairing. Calibration: vertical, 10 a.p./sec; horizontal, 1 sec. $B$, During pairing, the $+16^{\circ}$ stimulus was associated with a $+25 \mathrm{nA}$ current (triangles). No current was delivered during stimulation with the $-16^{\circ}$ stimulus (this disparity was almost ineffective in triggering the cell's response after the two first $S^{-}$ pairings). A cross-depression effect affecting $S^{0}$ and nearby disparities was found immediately following pairing, and the consequent shift of the relative preference of the cell for the $+16^{\circ}$ stimulus was still present the next $110 \mathrm{~min}$. $M$, These "theoretical" PSTHs were reconstructed by linearly adding the PSTHs obtained independently for each monocular component of the corresponding dichoptic stimulus (see inset in Fig. 1c), before and after pairing. They were not established during pairing since only the two dichoptic stimuli were presented. No changes were observed in the monocular responses.

$\mathrm{S}^{+}$disparity configuration (not shown). This additional orientation-dependent effect was transient, and no subsequent change was observed after the second and third pairings, indicating that the ulterior modifications in IOD selectivity, which were amplified by the successive pairings, were independent of the evolution of the monocular responses (compare $\mathrm{M}$ and $\mathrm{B}$ in Fig. 8).

The temporal evolution of the relative preference ratio between the disparities used during pairing (iterative stimulation) leads to general conclusions similar to those derived from the IOD tuning curves (randomized stimulation). Before the third pairing, the mean value of the IOD bias ratio calculated from the binocular responses was already slightly higher than that predicted by the sum of the monocular responses, this effect being already induced by the first two pairings (see Fig. 8). After pairing, both ratios $\left(\mathrm{IOD}_{\mathrm{B}}\right.$ and $\mathrm{IOD}_{\mathrm{M}}$ ) shifted in favor of the $\mathrm{S}^{+}$ disparity. However, the time course of these changes was different, since the $\mathrm{IOD}_{\mathrm{M}}$ ratio increased (toward $\mathrm{S}^{+}$) immediately after pairing and decayed progressively, reaching its initial level 110 min after pairing (see Fig. $10, M$ ). In contrast, the $\operatorname{IOD}_{\mathrm{B}}$ ratio-established from the binocular responses-increased progressively during the first $3 \mathrm{~min}$ and did not show any extinction (see Fig. 10, B). Remarkably, a reversibility of the cffect could be demonstrated using a reverse pairing protocol (inverting $\mathrm{S}^{+}$ and $S^{\circ}$ disparities) and this latter change affected only the binocular responses (see the two lower rows in Fig. 9).

Depending on the cell, competitive changes in IOD selectivity could correspond not only to modification of the preferred dis- 

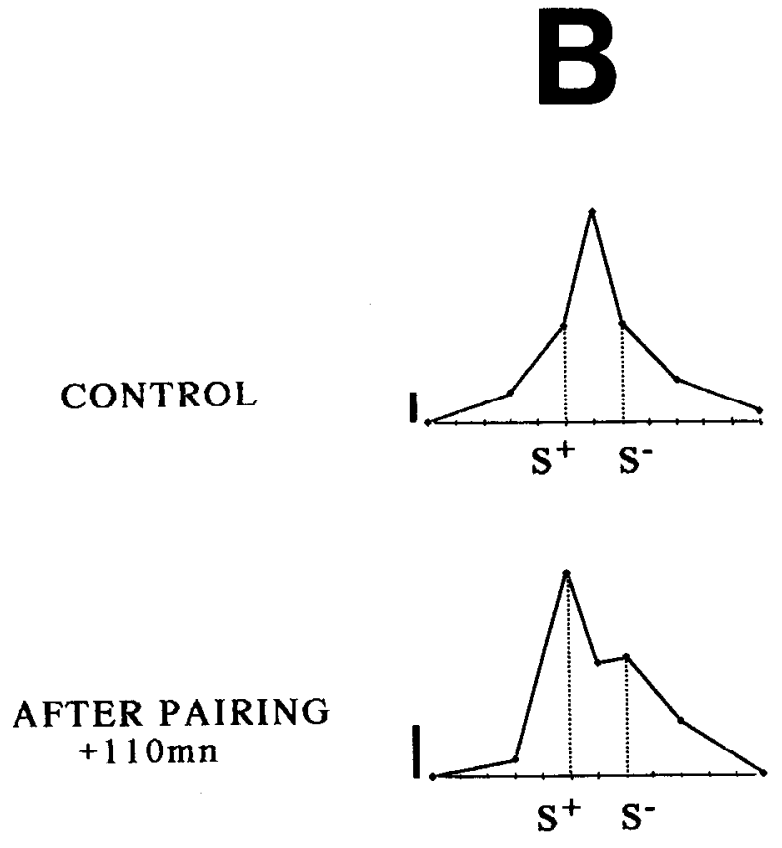

AFTER PAIRING $+110 \mathrm{mn}$

\section{CONTROL}

NORMALIZED

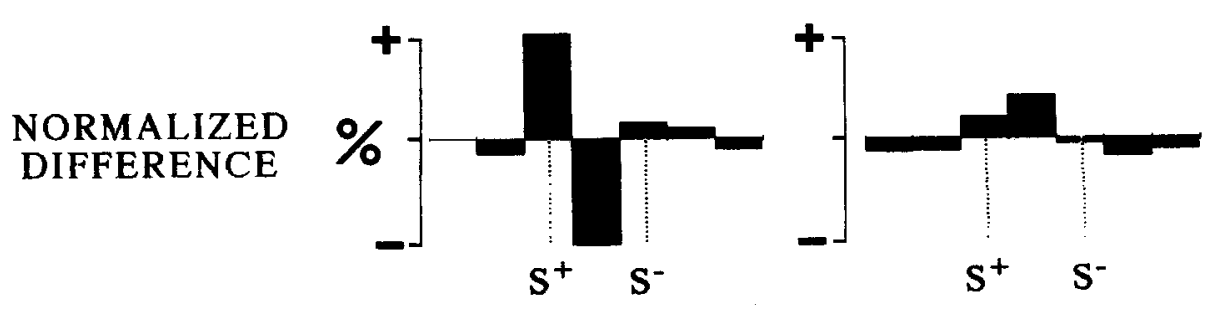

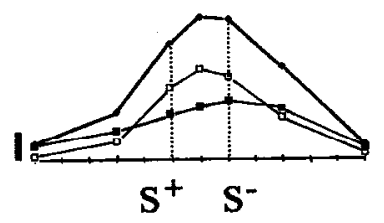
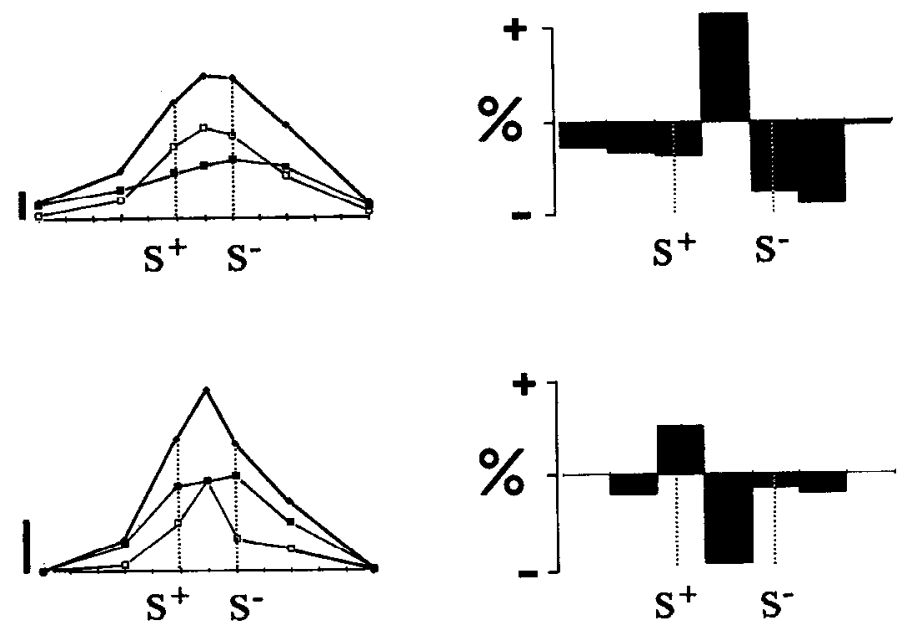

\section{BINOCULAR INTERACTION}

$\mathbf{s}^{+} \mathbf{s}^{-}$

Figure 11. Change in binocular interaction: cell recorded for $2 \mathrm{hr} 50 \mathrm{~min}$ in a 10-week-old normally reared kitten. The pairing procedure induced a significant shift of the preferred IOD toward the $\mathrm{S}^{+}$disparity. The selective facilitation for the null disparity was transformed after pairing into a selective occlusion for the initially preferred IOD accompanied by a selective facilitation for the reinforced disparity $\left(\mathrm{S}^{+}\right)$. $B, B$ Binocular IOD tuning curves before $(C O N T R O L)$ and after $(+110 \mathrm{mn})$ pairing. During pairing (not shown), the $-16^{\circ}\left(\mathrm{S}^{+}\right)$and the $+16^{\circ}\left(\mathrm{S}^{-}\right)$disparities were associated, respectively, with a $+10 \mathrm{nA}$ and a $-7 \mathrm{nA}$ current pulse. In the bottom row, the difference between normalized curves ("after" minus "before" pairing) demonstrates a selective gain in relative responsiveness for $\mathrm{S}^{+}$and a loss for the initially preferred disparity. Calibration: $\pm 20 \%$. $M$, The upper envelopes of each graph correspond to the theoretical IOD tuning curves given by the sum of the monocular responses, before (CONTROL) and after pairing $(+110 \mathrm{mn}$ ). In addition, each monocular tuning curve (with inverted abcissa for each eye to comply with the computation of the IOD response) is also presented on the same graph in order to compare the separate evolution of the contributions of the left eye (open squares) and right eye (solid squares) responses. The difference between normalized IOD tuning curves before and after pairing indicates no significant change in the sum of the monocular responses. Calibration: $\pm 20 \%$. Binocular interaction, The differences between the normalized binocular $(B)$ and monocular $(M)$ tuning curves were calculated before $(C O N T R O L)$ and after pairing $(+110 \mathrm{mn})$. The cell initially showed a selective facilitation for the $0^{\circ}$ disparity and a relative occlusion for all other disparities (upper graph). After pairing (lower graph), the selective facilitation shifted toward the disparity associated with a high level of activity $\left(\mathrm{S}^{+}\right)$and a loss of responsiveness appeared for the initially preferred disparity $\left(0^{\circ}\right)$. Calibration: $\pm 40 \%$. For the abscissa of tuning curves and normalized differences, see Figure 9.

parity, but also to a change in the type of binocular interaction (occlusion, facilitation), as shown in Figure 11. This cell, recorded in a 72-d-old normally reared kitten, was selective to orientation and initially dominated by the contralateral (left) eye. During the first control period it showed a clear facilitation for the null disparity with an occlusion for all other disparities tested (see upper row in Fig. 11). Immediately after pairing, a selective occlusion developed for the null disparity (not shown). One hundred and ten minutes later, this effect was still present, and a selective facilitation appeared gradually for the disparity associated with the high level of discharge $\left(\mathbf{S}^{+}\right.$; see middle row in Fig. 11). These changes could not be explained by selective adaptation in the orientation selectivity of each monocular response (see $\mathrm{M}$ in Fig. 11). However, this modification in bin- ocular integration was accompanied in this case by an overall change in ocular dominance, the cell becoming morc cqually activated by each eye.

Among the 15 cells submitted to one or more pairings, 6 showed a significant change in the orientation disparity tuning curve, which resulted for 5 of them in a shift in the preferred orientation disparity. Four out of the 6 modified cells displaced their tuning preference toward the disparity associated with a high level of discharge ( $\mathbf{S}^{\prime}$ ), and 1 toward the $\mathbf{S}^{-}$disparity. The binocular response of another cell showed an increased selectivity for the initially preferred disparity, although this effect was not seen in the monocular responses that became tuned to the orientations corresponding to the $\mathrm{S}^{+}$disparity. The quality of the control of postsynaptic activity during pairing appeared 
to be a relevant factor in the induction of functional modifications. No change was observed following pairing procedures that had been ineffective in modulating the postsynaptic activity of the recorded cell during iontophoresis. IOD changes were found in $33 \%$ of the cells with a "partial" control of activity, that is, when one polarity of iontophoretic current was effective, and in 57\% for cells where the control of activity during pairing was "complete" (see Materials and Methods in Frégnac et al., 1992). However, in the former case, changes were not always restricted to the "paired" disparity configuration: Figure 9 illustrates the casc of a possible cross-depression effect (sec also Tsumoto and Suda, 1979) developing for nonreinforced opposite disparities ( $S^{0}$, third pairing).

A second finding that argues for the specific and associative nature of the functional modifications is the observation that binocular responses were affected to a much larger extent than monocular ones and could not be predicted from the simple sum of the responses to each monocular component of the dichoptic stimulus. In half of these modified cells, these changes were expressed only in the viewing condition corresponding to that during which control of activity was imposed (i.e., dichoptic stimulation). These conclusions appear to be a general observation, since a similar distinction between binocular and monocular tuning modifications is evident when comparing IOD tuning changes in all modified neurons (Fig. 12). A relative gain in responsiveness was found in the $\mathrm{S}^{+}$region and the loss was confined to the $\mathrm{S}^{-}$rcgion for the binocular rcsponses, whercas monocular responses indicate no significant change in the preferred IOD.

In addition to such specific functional alterations, global changes in the mean level of activity of some cells could be observed over time but seemed to be nonassociative in nature. A similar proportion of changes in excitability was found in paired cells, affected or unaffected by the pairing procedure (respectively, $71.5 \%$ and $80 \%$ of cases). A depression or an increase in the mean level of spontaneous and visual activity was observed in equal proportions. In two out of six cells, the changes in IOD were not accompanied by any change in global excitability.

Depending on the cell and the recording time, these changes were still present $35-135 \mathrm{~min}$ following the last pairing. In one case an extinction of the effect was observed after $80 \mathrm{~min}$ of control stimulation. This study was done exclusively in normally reared kittens. No modification of the selectivity to the IOD was observed in two cells recorded at 4 weeks of age. Changes could be induced from 7-15 weeks of age, and no age dependence in the amplitude of the effects was observed during this latter period.

\section{Discussion}

This experiment demonstrates, as for the case of ocular dominance, that an exogenous control of postsynaptic activity can induce long-term changes in interocular orientation disparity during the time of recording of a single cell. Six out of 15 cells adapted their binocular responses (40\%), which resulted for five of them $(83 \%)$ in a reorganization of the selectivity of the tuning for IOD. A gain in relative responsiveness toward $\mathrm{S}^{+}$was observed in four out of the six modified cells $(67 \%)$. The functional effects werc cstablished on a more restricted sample than using simpler pairing protocols (see experiment 1 and Frégnac et al., 1992) because of the longer duration of control recording required.

\section{NORMALIZED DIFFERENCE}
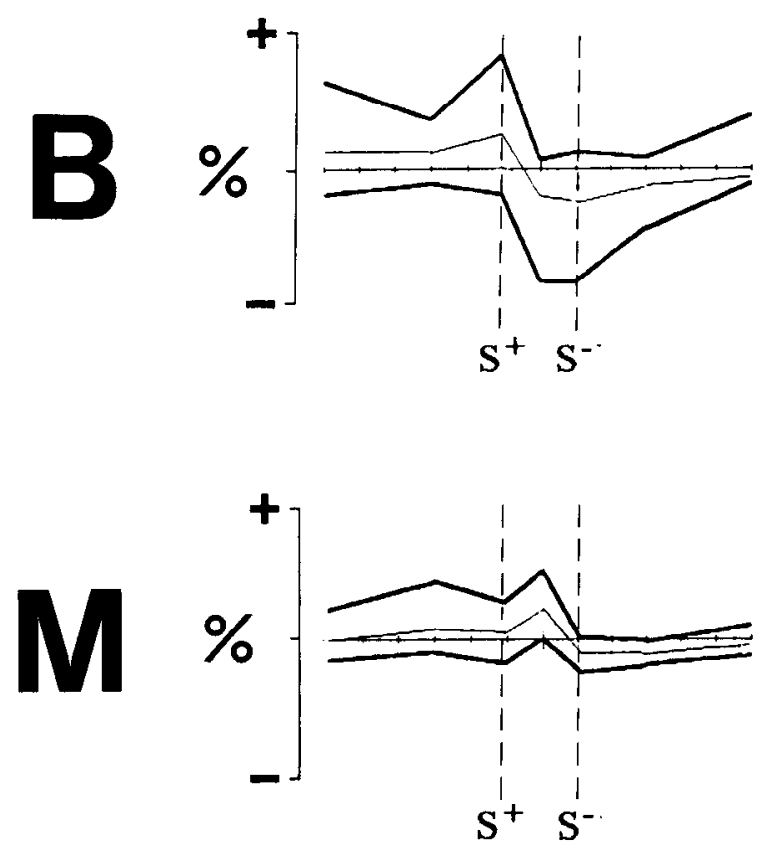

Figure 12. Comparison of binocular and monocular changes in relative responsiveness to IOD. A global normalized difference analysis was performed for all the modified cells on both $\operatorname{binocular}(B)$ and monocular $(M)$ responses. From the computation for each cell of the difference between normalized IOD tuning curves before and after pairing as a function of disparity, three "population" curves are represented on the same graph: (1) the mean values of the relative gains and losses for each disparity (thin line) and (2 and 3) upper and lower envelopes of the extreme values (thick lines). All curves established in the binocular viewing condition $(B)$ indicate that, on average, a gain in relative responsiveness developed after pairing in favor of the $\mathrm{S}^{+}$disparity, and was accompanied by a loss selectively centered on the $\mathrm{S}^{-}$disparity. In contrast, no significant change was found when applying the same analysis to the sum of the monocular responses $(M)$. Abscissa for $B$ and $M$, disparity values between the orientations presented to each eye (from left to right): $-90^{\circ},-45^{\circ},-16^{\circ}, 0^{\circ},+16^{\circ},+45^{\circ},+90^{\circ}$. The $\mathrm{S}^{+}$and $\mathrm{S}^{-}$ disparities are indicated by broken lines. Vertical calibration, $\pm 25 \%$.

Our artificial procedure of local conditioning was intented to mimic the protocol originally devised by Shinkman and colleagues (reviewed in Shinkman et al., 1985). These authors allowed dark-reared kittens to experience daily brief periods of normal vision independently through each eye, by interposing prisms that optically rotated each monocular visual field in opposite directions. In those kittens, electrophysiological analysis of orientation preferences restricted to cells analyzing central vision showed a bias in the distribution of IODs, which was centered around the disparity value imposed by the prism (Shinkman and Bruce, 1977; Shinkman et al., 1980). Such adaptive behavior was observed for optical disparities smaller than $20^{\circ}$. For disparities beyond $30^{\circ}$, there was generally a breakdown of binocularity. For the few remaining binocular cells, the mean IOD did not reflect that imposed by the prisms. Most cells in this latter case presented nonoriented receptive fields, and a majority of the monocular cells that were selective to orientation had a preference for horizontal and vertical orientations (Isley et al., 1990). This plasticity of the orientation cortical network 
was retained until 4-5 months of age in kittens otherwise maintained in darkness (Shinkman et al., 1983).

The largest IOD value to which binocular cortical cells can adapt corresponds closely to the range of disparity spanned by the IOD distribution observed in the normal adult cat $\left(15-20^{\circ}\right)$. This value may represent the limit of the system to integrate discordant information from both eyes in the orientation domain. Interestingly, this is the total angular deviation of the images in the two eyes that can be reached in the cat for some extreme viewing conditions (Bishop, Elekesy, and Nelson, cited in Nelson et al., 1977). The disparities used in our experiments are within this limit (since before pairing the optimal disparity was zero), and according to Shinkman and colleagues, no breakdown of the binocularity is expected. Indeed, among the 11 binocular cells from which monocular responses from each age could be recorded before and after pairing, only one became monocularly activated. Seven other cells remained binocular and did not change their ocular dominance class. The last three cells, initially dominated by one eye, became equally activated through each eye.

Our study of the adaptive capacities of binocular interaction using the simultaneous recording of monocular and binocular responses leads us to additional conclusions beyond those already reached by Shinkman and collaborators, who limited their analysis of binocular integration to ocular dominance assessment. Our own data show that in most cases binocular interaction was affected to a much greater extent than were monocular responses. In some cases we could demonstrate a complete independence in the temporal evolution of the binocular response versus that of the monocular responses. This pleads for the associative nature of the modifications, since they were expressed only under the viewing condition that was used during pairing. However, in view of the limited time of recording from our cells, one cannot rule out the possibility that this remarkable adaptation of binocular interaction precedes a more permanent modification of the monocular responses, possibly resulting in a differential shift of the preferred orientations seen through each eye, such as that described by Shinkman and co-workers (Shinkman and Bruce, 1977; Shinkman et al., 1983, 1985). Note that this latter effect was observed, after having imposed a given interocular disparity for periods longer than $50 \mathrm{hr}$, distributed over a 1-2 month period.

\section{General Discussion}

The functional effects described at the single-unit level in both experiments appear to be closely related to the global modifications of cortical selectivity induced by restricted rearing procedures. Nevertheless, in spite of the analogy in the observed response property modifications, the supervised learning proccdures we have developed differ in an important way from natural manipulation of visual environment: in our cellular paradigms, competition is introduced by biasing the postsynaptic signal, whereas environmental procedures known to modify ocular dominance (monocular deprivation, optical strabismus, and prism rearing) act primarily on the presynaptic signals. Strabismus, for instance, corresponds to a situation where both receptive fields are stimulated and, on average, no competitive advantage is given to one eye. In contrast, monocular deprivation consistently favors connections subserving the same (open) eye. In that respect the protocol of experiment 1 likens the $\mathrm{S}^{+}$situation to monocular deprivation. On the other hand, strabismus and prism rearing result in an incongruity in the afferent bin- ocular message in either the spatial or orientation domain. Both situations address specifically interocular competition during unmatched binocular input, an issue that was dealt with in experiment 2.

Most of the changes reported in our experiments were in favor of the positively reinforced stimulus $(87.5 \%$ for ocular dominance and $67 \%$ for IOD). The fact that their outcome was clearly dependent on the sign of the imposed control of activity during pairing argues for the specificity of the induced functional modifications. These observations agree with the prediction of our working hypothesis (see Frégnac et al., 1992): the most plausible interpretation is that the observed changes in ocular dominance and in IOD reflect relatively long-term modifications in the efficacy of synaptic transmission of excitatory connections.

$\mathrm{S}^{+}$and synaptic potentiation. Several lines of physiological evidence support the assumption that area 17 synapses can undergo potentiation when the covariance level between pre- and postsynaptic activity becomes positive. Persistent changes in evoked cortical potentials could be induced by repetitive electrical stimulation of one optic nerve (Tsumoto and Suda, 1979). Visual cortical responses were enhanced in response to stimulation of the conditioned optic nerve and were cross-depressed in response to stimulation of the nonconditioned optic nerve. This report, which was the first to show that visual pathways may sustain potentiation, should be compared to the $\mathrm{S}^{+}$situation in our experiments. The repetitive long-lasting stimulation of one optic nerve probably produces a massive activation of postsynaptic cortical cells, so that the afferents from the non-stimulated eye are silent while the target cell reaches a critical threshold of depolarization under the cooperative influence of the many fibers subserving the other eye. Consequently, potentiation and cross-depression could result from binocular synaptic competition of the kind proposed by Stent (1973) or the covariance hypothesis (column 2 in Table 1 in Frégnac et al., 1992). Enhancement in the efficacy of excitatory synaptic transmission was proposed as the most likely mechanism for the long-term potentiation observed after white matter stimulation in slices of kitten visual cortex (Artola and Singer, 1987) and also after LGN or optic chiasm stimulation in vivo (Komatsu et al., 1988).

$S^{-}$and synaptic depression. Although it is generally admitted that postsynaptic activation is a necessary requisite for any plastic change to occur (Rauschecker and Singer, 1981; Shaw and Cynader, 1984), the present study reports functional changes that take place during a reduction or even in the absence of postsynaptic cortical activity. Our findings are nevertheless in agreement with a recent work by Reiter and Stryker (1988), which shows that a change in ocular dominance can be induced in favor of the deprived eye when monocular deprivation is associated with an inactivation of cortical cells by infusion of the GABA agonist muscimol. These latter data demonstrate that it is possible to put the closed eye at a competitive advantage over the experienced eye. This situation is comparable to that obtained locally in our experiments during an imposed negative covariance level $\left(\mathrm{S}^{-}\right)$, produced by the blockade or reduction of the cortical response (see Figs. $5 a ; 7$, first pairing). Both studies support the assumption that repetitive failure of the nondeprived afferent fibers in activating the postsynaptic cell should induce a decrease in the efficacy of the synaptic transmission of the active synapses.

In conclusion, the study reported here is a quantitative demonstration, at the level of individual neurons, of functional 
changes analogous to those described classically during epigenesis of visual cortex. Our data illustrate the capacity of certain binocular cells to undergo significant shifts in ocular dominance in favor of the eye put at a competitive advantage, as well as selective changes in the binocular integration favoring the positively reinforced orientation disparity. More unexpectedly, our study suggests that a significant level of plasticity is retained in the adult neuron. This favors the hypothesis that Hebbian-like mechanisms that have been shown to be important during the functional epigenesis of visual cortex could be operational throughout the life of the animal. We suggest that, in the intact animal, extraretinal gating signals such as noradrenaline and extraocular proprioceptive inflow - substituted by our pairing protocols-produce effective covariance changes as a result of normal visuomotor experience during a postnatal critical period in kittens (Trotter et al., 1987; reviewed in Frégnac and Shulz, 1989) or during selective periods of learning in the adult (see also Kasamatsu et al., 1985). These would allow cortical neurons to undergo a functional transition from a passive relay mode of transmission to an adaptive state reached only below or above certain levels of membrane potential. It still remains to be determined why there is an age dependence in the expression of this experience sensitivity in the intact behaving animal, and no age dependence in the probability of inducing changes using our experimental paradigm. This issue depends critically on the unsupervised nature of neural events occurring during normal development and learning versus the supervised protocol applied here where iontophoretic action is artificially supplied. In the behaving animal the progressive reinforcement of local inhibitory intracortical networks with age (Komatsu and Iwakiri, 1991), and a lesser dependence of visual responses on the activation of NMDA receptors the older the animal (Tsumoto et al., 1987; Fox et al., 1989) could provide possible mechanisms reducing the efficacy of detection and of transduction of covariance changes between pre- and postsynaptic activity after the end of the critical period.

\section{References}

Artola A, Singer W (1987) Long-term potentiation and NMDA receptors in rat visual cortex. Nature 330:649-652.

Bienenstock F, Conper I.N, Munro P (1982) Theory for the development of neuron selectivity: orientation specificity and binocular interaction in visual cortex. $\mathrm{J}$ Neurosci $2: 23-48$.

Bishop PO, Henry GH, Smith CJ (1971) Binocular interaction ficlds of single units in the cat striate cortex. J Physiol (Lond) 216:39-68.

Blakemore C, Van Sluyters RC (1974) Reversal of the physiological effects of monocular deprivation in kittens: further evidence for a sensitive period. J Physiol (Lond) 237:195-216.

Blakemore C, Van Sluyters RC (1975) Innate and environmental factors in the development of the kitten's visual cortex. J Physiol (Lond) 248:663-716.

Blakemore C, Van Sluyters RC, Movshon JA (1976) Synaptic competition in the kitten's visual cortex. Cold Spring Harbor Symp Quant Biol 40:601-609.

Blakemore C, Fiorentini A, Maffei L (1972) A second neural mechanism of binocular depth discrimination. J Physiol (Lond) 226:727749 .

Buisseret P, Gary-Bobo E, Imbert M (1978) Evidence that ocular motility is involved in the recovery of the orientational properties of visual cortical neurones in dark reared kittens. Nature 272:816-817.

Chapman B, Jacobson MD, Reiter HO, Stryker MP (1986) Ocular dominance shift in kitten visual cortex caused by imbalance in retinal electrical activity. Nature 324:154-156.

Cynader M, Mitchell DE (1977) Monocular astigmatism effects on kitten visual cortex development. Nature 270:177-178.

Cynader M, Mitchell DE (1980) Prolonged sensitivity to monocular deprivation in dark-reared cats. J Neurophysiol 43:1026-1040.
Diamond DM, Weinberger NM (1986) Classical conditioning rapidly induces specific changes in frequency receptive fields of single neurons in secondary and ventral ectosylvian auditory cortical fields. Brain Res 372:357-360.

Dürsteler MR, von der Heydt R (1983) Plasticity in the binocular correspondence of striate cortical receptive fields in kittens. J Physiol (Lond) 345:87-105.

Fox K, Daw N, Sato H (1989) The location and function of NMDA receptors in cat and kitten visual cortex. J Neurosci 9:2443-2454.

Freeman RD, Ohzawa I (1990) On the neurophysiological organization of binocular vision. Brain Res 30:1661-1676.

Freeman RD, Olson CR (1979) Is there a "consolidation" effect for monocular deprivation. Nature 282:404-406.

Frégnac Y, Bienenstock E (1981) Specific functional modifications of individual cortical neurones, triggered by vision and passive eyemovement, in immobilized kittens. In: Pathophysiology of the visual system (Maffei L, ed), pp 100-108. Pisa: Junk.

Frégnac $Y$, Imbert $M$ (1984) Development of neuronal selectivity in primary visual cortex of cat. Physiol Rev 64:325-434.

Frégnac Y, Shulz D (1987) A cellular analog of developmental visual cortical plasticity. Soc Neurosci Abstr 13:1241.

Frégnac Y, Shulz D (1989) Hebbian synapses in visual cortex. In: Seeing contour and colour (Kulikowski JJ, ed), pp 711-718. Paris: Pergamon.

Frégnac Y, Shulz D, Thorpe S, Bienenstock E (1988) A cellular analogue of visual cortical plasticity. Nature 333:367-370.

Frégnac Y, Shulz D, Thorpe S, Bienenstock E (1992) Cellular analogs of visual cortical epigenesis. I. Plasticity of orientation selectivity. J Neurosci 12:1280-1300.

Gardner JC, Douglas RM, Cynader MS (1985) A time-based stereoscopic depth mechanism in the visual cortex. Brain Res 328:154157.

Gilbert CD, Wiesel TN (1991) Dynamic properties of visual cortical cells. In: NATO advanced research workshop, Physiological and computational aspects of cortical functions, pp 28-29. Sirolo, Italy.

Greuel JM, Luhmann HJ, Singer W (1988) Pharmacological induction of use dependent receptive field modifications in the visual cortex. Science 242:74-77.

Hammond $P$ (1981) Non-stationarity of ocular dominance in cat striate cortex. Exp Brain Res 42:189-195.

Hebb DO (1949) The organization of behavior. New York: Wiley.

Hubel DH, Wiesel TN (1962) Receptive field binocular interaction and functional architecture in the cat's visual cortex. J Physiol (Lond) 160:106-154.

Hubel DH, Wiesel TN (1965) Binocular interaction in striate cortex of kittens reared with artificial squint. J Neurophysiol 28:1041-1059.

Hubel DH, Wiesel TN (1970) The period of susceptibility to the physiological effects of unilateral eye closure in kittens. J Physiol (Lond) 206:419-436.

Isley MR, Rogers-Ramachandran DC, Shinkman PG (1990) Interocular torsional disparity and visual cortical development in the cat. J Neurophysiol 64:1352-1360.

Jones KR, Spear PD, Tong L (1984) Critical periods for effects of monocular deprivation: differences between striate and extrastriate cortex. J Neurosci 4:2543-2552.

Kasamatsu T (1976) A long-lasting change in ocular dominance of kitten striate neurons induced by reversible unilateral blockage of tonic retinal discharges. Exp Brain Res 26:487-494.

Kasamatsu T, Watabe K, Heggelund P, Schöller E (1985) Plasticity in cat visual cortex restored by electrical stimulation of the locus coeruleus. Neurosci Res 2:365-386.

Kato H, Bishop PO, Orban GA (1981) Binocular interaction on monocularly discharged lateral geniculate and striate neurons in the cat. J Neurophysiol 46:932-951.

Komatsu Y, Iwakiri M (1991) Postnatal development of neuronal connections in cat visual cortex studied by intracellular recording slice preparation. Brain Res 540:14-24.

Komatsu Y, Fujii K, Maeda J, Sakaguchi H, Toyama K (1988) Longterm potentiation of synaptic transmission in kitten visual cortex. J Neurophysiol 59:124-141.

LeVay S, Stryker MP, Shatz CJ (1978) Ocular dominance columns and their development in layer IV of the cat's visual cortex: a quantitative study. J Comp Neurol 179:223-244.

Leventhal AG, Hirsch HVB (1980) Receptive field properties of dif- 
ferent classes of neurons in visual cortex of normal and dark-reared cats. J Neurophysiol 43:1111-1132.

Macy A, Ohzawa I, Freeman RD (1982) A quantitative study of the classification and stability of ocular dominance in the cat's visual cortex. Exp Brain Res 48:401-408.

Merzenich MM, Nelson RJ, Stryker MP, Cynader MS, Schopmann A, Zook JM (1984) Somatosensory cortical map changes following digit amputation in adult monkeys. J Comp Neurol 224:591-605.

Mioche L, Singer W (1989) Chronic recordings from single sites of kitten striate cortex during experience-dependent modifications of receptive field properties. J Neurophysiol 62:185-197.

Movshon JA, Dürsteler MR (1977) Effects of brief periods of unilateral eye closure on the kitten's visual system. J Neurophysiol 40:12551265.

Movshon JA, Van Sluyters RC (1981) Visual neural development. Annu Rev Psychol 32:477-522.

Nelson JI, Kato H, Bishop PO (1977) Discrimination of orientation and position disparities by binocularly activated neurons in cat striate cortex. J Neurophysiol 40:260-283.

Olson CR, Freeman RD (1980) Profile of the sensitive period for monocular deprivation in kittens. Exp Brain Res 39:17-21.

Orban GA (1984) Neuronal operations in the visual cortex, p 117. Berlin: Springer.

Pettigrew JD, Nikara T, Bishop PO (1968) Responses to moving slits by single units in cat striate cortex. Exp Brain Res 6:373-390.

Pettigrew JD, Olson C, Barlow HB (1973) Kitten visual cortex: shortterm, stimulus-induced changes in connectivity. Science 180:12021203.

Rauschecker JP, Singer W (1981) The effects of early visual experience on the cat's visual cortex and their possible explanation by Hebb synapses. J Physiol (Lond) 310:215-239.

Reiter HO, Stryker MP (1988) Neural plasticity without postsynaptic action potentials: less-active inputs become dominant when kitten visual cortical cells are pharmacologically inhibited. Proc Natl Acad Sci USA 85:3623-3627.

Schechter PB, Murphy EH (1976) Brief monocular visual experience and kitten cortical binocularity. Brain Res 109:165-168.

Shaw C, Cynader M (1984) Disruption of cortical activity prevents ocular dominance changes in monocularly deprived kittens. Nature 308:731-733.

Shinkman PG, Bruce CJ (1977) Binocular differences in cortical receptive fields of kitten after rotationally disparate binocular experience. Science 197:285-287.

Shinkman PG, Isley MR, Rogers DG (1980) Cortical binocular receptive fields in developing kittens: effects of early visual field rotation followed by normal visual exposure during adulthood. In: Proceedings of the 28th International Congress on Physiological Science, Vol 4, p 700 . Budapest.

Shinkman PG, Isley MR, Rogers DG (1983) Prolonged dark rearing and devclopment of interocular oricntation disparity in the visual cortex. J Neurophysiol 49:717-729.

Shinkman PG, Isley MR, Rogers DG (1985) Development of interocular relationships in visual cortex. In: Advances in neural and behavioral development (Aslin R, ed), pp 187-268. Norwood, NJ: Ablex.

Shulz D (1987) A cellular analog of functional plasticity in the visual cortex: study on the neuronal mechanisms of epigenesis and learning (in French). $\mathrm{PhD}$ thesis, Université Paris-Sud.

Sillito AM, Kemp JA, Patel H (1980) Inhibitory interactions contributing to the ocular dominance of monocularly dominated cells in the normal cat striate cortex. Exp Brain Res 41:1-10.

Singer W (1977) Effects of monocular deprivation on excitatory and inhibitory pathways in cat striate cortex. Exp Brain Res 30:25-41.

Stent G (1973) A physiological mechanism for Hebb's postulate of

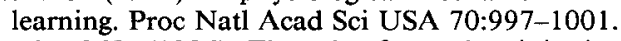

Stryker MP (1986) The role of neural activity in rearranging connections in the central visual system. In: The biology of change in otolaryngology (Ruben RW, ed), pp 211-224. Amsterdam: Elsevier.

Trotter Y, Frégnac Y, Buisseret P (1983) Synergy between vision and extraocular proprioception in gating functional plasticity of kitten primary visual cortex. C R Acad Sci Ser III Sci Vie 296:665-668.

Trotter Y, Frégnac Y, Buisseret P (1987) The period of susceptibility of visual cortical binocularity to unilateral proprioceptive deafferentation of extraocular muscles. J Neurophysiol 58:795-815.

Tsumoto T, Freeman RD (1981) Ocular dominance in kitten cortex: induced changes of single cells while they are recorded. Exp Brain Res 44:347-351.

Tsumoto T, Suda K (1979) Cross-depression: an electrophysiological manifestation of binocular competition in the developing visual cortex. Brain Res 168:190-194.

Tsumoto T, Hagihara K, Sato H, Hata Y (1987) NMDA receptors in the visual cortex of young kittens are more effeclive than those of adult cats. Nature 327:513-514.

Van Sluyters RC, Levitt FB (1980) Experimental strabismus in the kitten. J Neurophysiol 43:686-699.

Von der Malsburg C (1973) Self-organization of orientation sensitive cells in the striate cortex. Kybernetik 14:85-100.

Wiesel TN, Hubel DH (1963) Single-cell responses in striate cortex of kittens deprived of vision in one eye. J Neurophysiol 26:10031017. 